\title{
Article \\ Shikonin Reduces Growth of Docetaxel-Resistant Prostate Cancer Cells Mainly through Necroptosis
}

\author{
Sascha D. Markowitsch ${ }^{1}$, Kira M. Juetter ${ }^{1}$, Patricia Schupp ${ }^{1}$, Kristine Hauschulte ${ }^{1}$, Olesya Vakhrusheva ${ }^{1}$, \\ Kimberly Sue Slade ${ }^{1}$, Anita Thomas ${ }^{1}$, Igor Tsaur ${ }^{1}{ }^{(D}$, Jindrich Cinatl, Jr. ${ }^{2}$, Martin Michaelis ${ }^{3} \mathbb{D}$, Thomas Efferth ${ }^{4}$, \\ Axel Haferkamp ${ }^{1}$ and Eva Juengel ${ }^{1, *}$
}

1 Department of Urology and Pediatric Urology, University Medical Center Mainz, Langenbeckstraße 1, 55131 Mainz, Germany; sascha.markowitsch@unimedizin-mainz.de (S.D.M.); kjuetter@students.uni-mainz.de (K.M.J.); pschupp@students.uni-mainz.de (P.S.); kristine.hauschulte@gmx.de (K.H.); olesya.vakhrusheva@unimedizin-mainz.de (O.V.); kimberlysue.slade@unimedizin-mainz.de (K.S.S.); anita.thomas@unimedizin-mainz.de (A.T.); igor.tsaur@unimedizin-mainz.de (I.T.); axel.haferkamp@unimedizin-mainz.de (A.H.)

2 Institute of Medical Virology, Goethe-University, 60596 Frankfurt, Germany; cinatl@em.uni-frankfurt.de

3 Industrial Biotechnology Centre and School of Biosciences, University of Kent, Canterbury CT2 7NJ, UK; M.Michaelis@kent.ac.uk

4 Institute of Pharmaceutical and Biomedical Sciences, Johannes Gutenberg University Mainz, Staudingerweg 5, 55128 Mainz, Germany; efferth@uni-mainz.de

* Correspondence: eva.juengel@unimedizin-mainz.de; Tel.: +49-631-175433; Fax: +49-6131-174410

\section{check for} updates

Citation: Markowitsch, S.D.; Juetter, K.M.; Schupp, P.; Hauschulte, K.; Vakhrusheva, O.; Slade, K.S.; Thomas, A.; Tsaur, I.; Cinatl, J., Jr.; Michaelis, M.; et al. Shikonin Reduces Growth of Docetaxel-Resistant Prostate Cancer Cells Mainly through Necroptosis. Cancers 2021, 13, 882. https:// doi.org/10.3390/cancers13040882

Academic Editor:

Isabel Heidegger-Pircher

Received: 18 December 2020

Accepted: 15 February 2021

Published: 20 February 2021

Publisher's Note: MDPI stays neutral with regard to jurisdictional claims in published maps and institutional affiliations.

Copyright: (c) 2021 by the authors. Licensee MDPI, Basel, Switzerland This article is an open access article distributed under the terms and conditions of the Creative Commons Attribution (CC BY) license (https:// creativecommons.org/licenses/by/ $4.0 /)$.
Simple Summary: Prostate carcinoma $(\mathrm{PCa})$ is the most common tumor in men with an increasing age-associated risk. Several therapy strategies, one of which is docetaxel (DX) chemotherapy, have been established. However, due to the development of therapy resistance, in which chemotherapy no longer effectively combats the cancer, advanced, metastasized PCa with a poor prognosis may become manifested and therapy inevitably fails. Thus, new treatment options are urgently needed. Shikonin (SHI), from Traditional Chinese Medicine, has revealed promising antitumor activity in several tumor entities. In the current study, the impact of SHI on four therapy-sensitive and four respective DX-resistant PCa cell lines was determined. SHI induced growth inhibition mainly by necroptosis, a type of cell death, in all the tested therapy-sensitive, but more importantly, DX-resistant PCa cell lines. Corresponding molecular alterations contributing to growth inhibition after SHI exposure were found. SHI could, therefore, be a promising additive in treating advanced PCa.

Abstract: The prognosis for advanced prostate carcinoma (PCa) remains poor due to development of therapy resistance, and new treatment options are needed. Shikonin (SHI) from Traditional Chinese Medicine has induced antitumor effects in diverse tumor entities, but data related to PCa are scarce. Therefore, the parental (=sensitive) and docetaxel (DX)-resistant PCa cell lines, PC3, DU145, LNCaP, and 22Rv1 were exposed to SHI [0.1-1.5 $\mu \mathrm{M}]$, and tumor cell growth, proliferation, cell cycling, cell death (apoptosis, necrosis, and necroptosis), and metabolic activity were evaluated. Correspondingly, the expression of regulating proteins was assessed. Exposure to SHI time- and dose-dependently inhibited tumor cell growth and proliferation in parental and DX-resistant PCa cells, accompanied by cell cycle arrest in the G2/M or S phase and modulation of cell cycle regulating proteins. SHI induced apoptosis and more dominantly necroptosis in both parental and DX-resistant PCa cells. This was shown by enhanced pRIP1 and pRIP3 expression and returned growth if applying the necroptosis inhibitor necrostatin-1. No SHI-induced alteration in metabolic activity of the PCa cells was detected. The significant antitumor effects induced by SHI to parental and DX-resistant PCa cells make the addition of SHI to standard therapy a promising treatment strategy for patients with advanced PCa.

Keywords: prostate cancer (PCa); docetaxel (DX) resistance; shikonin (SHI); Traditional Chinese Medicine (TCM); growth inhibition; apoptosis; necroptosis 


\section{Introduction}

Prostate carcinoma (PCa) is the most common cancer and the second leading cause of cancer mortality in men, with increasing risk associated with age. Early detection programs in middle age and new therapeutic strategies are attempts to extend the life expectancy of PCa patients [1]. Despite the advantages of currently approved therapeutic strategies, advanced PCa remains an aggressive disease with poor prognosis. For high-risk, non-metastatic, and metastatic castration-resistant $\mathrm{PCa}$, the efficacy of the chemotherapeutic agent docetaxel (DX) was established [2] and approved as a "first-line" therapy after androgen deprivation therapy (ADT). In the following years, DX was further approved as a first-line therapy in combination with ADT [3]. A good response in high-risk non-metastatic PCa patients to DX applied together with ADT and radiation has been reported [4]. However, therapy resistance limits the effect of DX to a few months and failure inevitably occurs [5]. The efficacy in second-line treatment decreases considerably with therapy resistance [6].

Failure of conventional therapy prompts cancer patients to turn to traditional and alternative medicine $[7,8]$. Nearly half of cancer patients in Europe use complementary and alternative therapies [9-11], hoping to increase effectiveness or reduce the side effects of conventional therapy $[12,13]$. The turn to complementary medicine is critical, as reliable studies, and thus proven efficacy of natural substances, are often not available, leading to uncoordinated self-treatment. Lack of studies also increases the risk of unidentified contraindications and adverse side effects of the natural compounds combined with conventional therapy [14]. However, some studies have been carried out indicating antitumor effects of natural compounds, notably if applied together with an established therapy or by counteracting therapy resistance [15-21].

One natural compound that has revealed promising antitumor activity is shikonin (SHI). SHI is a herbal pigment traditionally used for the natural coloration of textiles and food. It is isolated from the dried roots of Lithospermum erythrorhizon. Several studies show that SHI, in addition to its function as a color pigment, has antimicrobial [22], antiinflammatory [23], and antitumor [24,25] activity.

The antitumor activity has been demonstrated in different tumor entities. In gastric cancer, cells exposed to SHI underwent cell cycle arrest in the G2/M phase [26]. SHI has induced apoptosis in gastric cancer [27] and pancreatic cancer [28] in vitro. Other types of regulated cell death have also been detected [29]. One of these is necroptosis and exposure to SHI in glioma [30], breast [31], and pancreatic cancer cells [28] has resulted in this type of regulated cell death. Necroptosis is a caspase-independent, programmed form of necrosis [32]. Receptor-interacting serine/threonine-protein kinase 1 and 3 (RIP1/RIP3) are relevant key players in this signaling pathway. Their activation is associated with the inactivation of caspase 8 , followed by mixed lineage kinase domain-like protein (MLKL) complex formation and degeneration of cell membranes and organelles [33]. In bladder cancer [34] and chronic myeloid leukemia cells [35], SHI led to a decrease in chemotherapy resistance through induction of necroptosis.

In addition, SHI exerted a direct influence on cell metabolism, specifically inhibiting pyruvate kinase isozymes M2 (PKM2) and directly or indirectly resulting in reduced growth of bladder cancer [34] and lung cancer in vitro [36] and in vivo [37]. SHI inhibited the mitochondrial activity of cancer cells [38]. However, data for SHI in PCa are sparse and not available for DX-resistant PCa cells. Thus, the current study was designed to evaluate the impact of SHI on the growth behavior of therapy-sensitive (parental) and DX-resistant PCa cells.

\section{Results}

\subsection{Shikonin Inhibited Cell Growth of Parental and DX-Resistant PCa Cells}

To determine the SHI concentration necessary to influence cell growth in the four parental and DX-resistant PCa cell lines (PC3, DU145, LNCaP, and 22Rv1), the cells were exposed to $\mathrm{SHI}$ ranging from 0.1 to $1.5 \mu \mathrm{M}$. A dose- and time-dependent growth inhibi- 
tion was apparent in all four cell lines, compared to their respective unexposed controls (Figure 1). A significant growth reduction of parental PC3 and DU145 cells with an IC50 of $0.37 \mu \mathrm{M}$ SHI after $72 \mathrm{~h}$ was determined (Figure $1 \mathrm{a}, \mathrm{c}$ ). The growth of DX-resistant PC 3 and DU145 cells was inhibited with an IC50 of $0.54 \mu \mathrm{M}$ and $0.55 \mu \mathrm{M} \mathrm{SHI}$ after $72 \mathrm{~h}$ treatment (Figure 1b,d), indicating that growth inhibition of the parental and DX-resistant PC3 and DU145 cells is similar, but slightly stronger in parental cells. However, for both parental and DX-resistant PC3 cells significant growth inhibition was first reached with $0.5 \mu \mathrm{M}$ SHI (Figure 1a,b). For parental and DX-resistant DU145 cells, considerable inhibition was achieved with $0.75 \mu \mathrm{M}$ SHI after $72 \mathrm{~h}$ incubation (Figure $1 \mathrm{~b}, \mathrm{c}$ ). For LNCaP cells, it was the other way around. Here, with an IC50 of $0.59 \mu \mathrm{M}$ (Figure 1d), parental LNCaP showed a lower response to SHI, comparable to DX-resistant PC 3 and DU145 cells. The DX-resistant LNCaP counterpart displayed a higher sensitivity with an IC50 of $0.32 \mu \mathrm{M}$ (Figure 1e). 22Rv1 revealed the lowest sensitivity to SHI with an IC50 of $1.05 \mu \mathrm{M}$ in the parental and an IC50 of $1.12 \mu \mathrm{M}$ in the DX-resistant cells after $72 \mathrm{~h}$ (Figure $1 \mathrm{~g}, \mathrm{~h}$ ). Statistically significant growth inhibition in 22Rv1 was reached only with the highest dose of $1.5 \mu \mathrm{M} \mathrm{SHI}$ (Figure 1h). Thus, for further investigation into the mechanisms responsible for the growth inhibitory activity of SHI, $0.5 \mu \mathrm{M}$ to $1.0 \mu \mathrm{M}$ SHI was used for PC3, DU145, and LNCaP cells and $0.5-1.5 \mu \mathrm{M}$ SHI for the $22 \mathrm{Rv} 1$ cells.

(a)

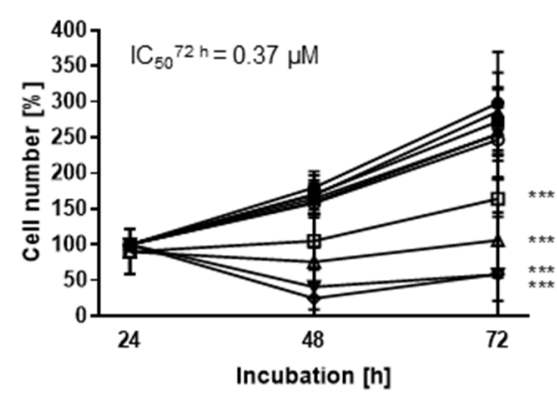

(c)

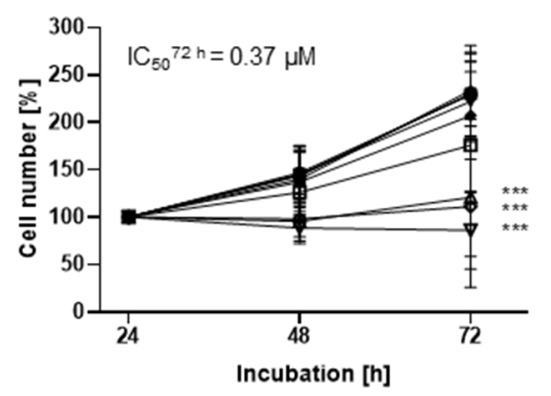

(e)

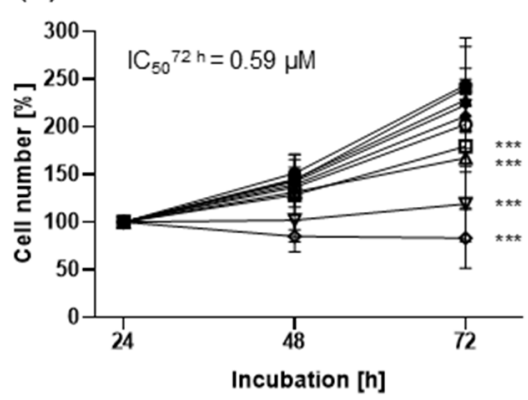

(b) PC3 res

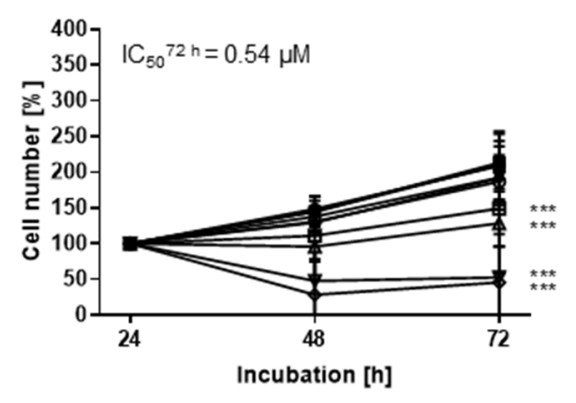

(d)

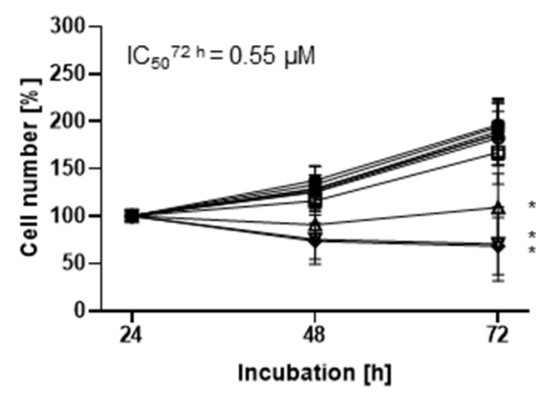

(f)

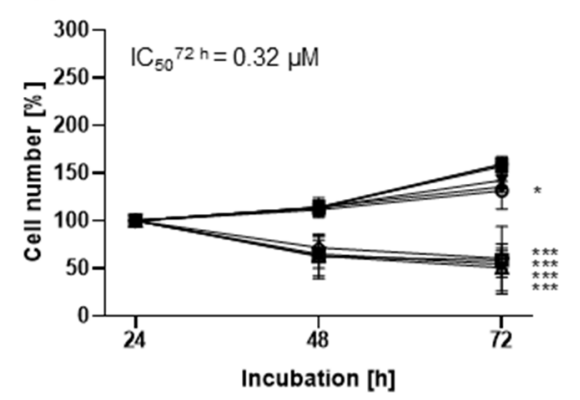

LNCaP res

$-\mathrm{CTRL}$
$-0.1 \mu \mathrm{M}$

$+0.15 \mu \mathrm{M}$

$\rightarrow 0.2 \mu \mathrm{M}$

$\rightarrow 0.25 \mu \mathrm{M}$

- $0.3 \mu \mathrm{M}$

․ $0.5 \mu \mathrm{M}$

$\Delta 0.75 \mu \mathrm{M}$

$\nabla-1 \mu \mathrm{M}$

$\diamond 1.5 \mu \mathrm{M}$

Figure 1. Cont. 
(g)

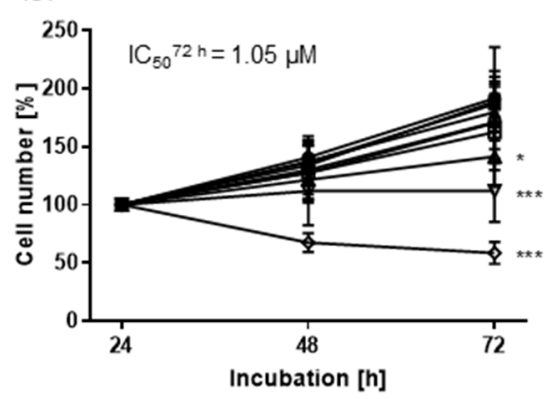

(h) 22Rv1 res

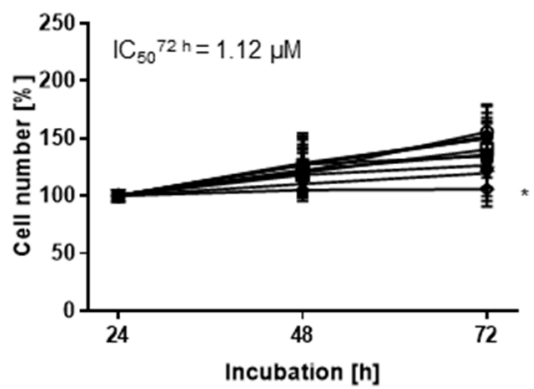

Figure 1. Tumor cell growth of parental (par) and DX-resistant (res) PC3 (a,b), DU145 (c,d), LNCaP (e,f), and 22Rv1 (g,h) cells after 24,48 , and $72 \mathrm{~h}$ exposure to shikonin (SHI) [0.1-1.5 $\mu \mathrm{M}]$. Cell number set to $100 \%$ after $24 \mathrm{~h}$ incubation. The IC50 of SHI after $72 \mathrm{~h}$ treatment is specified. Error bars indicate standard deviation (SD). Significant difference to untreated control: ${ }^{*}=p \leq 0.05,{ }^{* * *}=p \leq 0.001 . n=5$.

\subsection{Shikonin Impaired PCa Cell Proliferation}

Application of SHI for 24 and $48 \mathrm{~h}$ resulted in a dose-dependent inhibition of proliferation in all four investigated PCa cell lines (Figure 2). Analogous to growth, parental PC3 and DU145 cells showed a higher sensitivity to SHI, compared to their DX-resistant counterparts (Figure 2a-d). Most of the PCa cells already revealed strong or most potent effects after $24 \mathrm{~h}$ SHI treatment. However, parental DU145 cells responded better to SHI after $48 \mathrm{~h}$ exposure. In the DX-resistant subcells, first significant antiproliferative events were only apparent after $48 \mathrm{~h} \mathrm{SHI} \mathrm{application} \mathrm{(Figure} \mathrm{2c,d).} \mathrm{In} \mathrm{contrast,} \mathrm{treatment} \mathrm{of} \mathrm{both} \mathrm{parental}$ and DX-resistant LNCaP cells with $0.5 \mu \mathrm{M}$ SHI resulted in a significant inhibition of proliferation at all measured time points (Figure 2e,f). Proliferation was further suppressed with a higher SHI concentration. Similar to the growth experiments, 22Rv1 exhibited the lowest sensitivity to SHI, and the highest concentrations of $0.75 \mu \mathrm{M}$ and $1.0 \mu \mathrm{M}$ SHI were necessary to significantly reduce the proliferation of parental and DX-resistant $22 \mathrm{Rv} 1$ cells (Figure 2g,h).

(a)

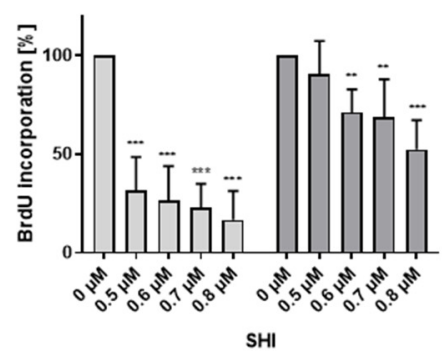

(c)

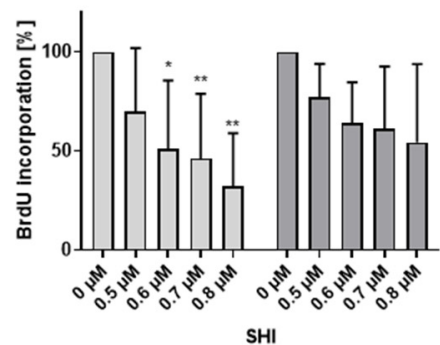

(b)

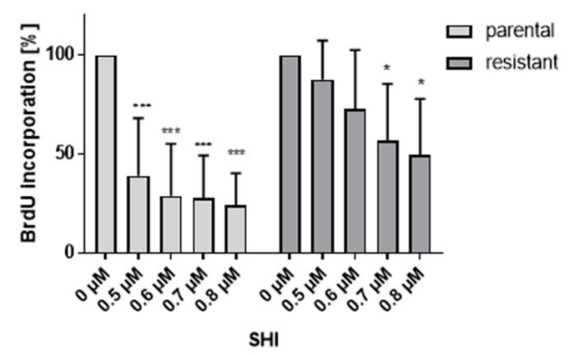

(d)

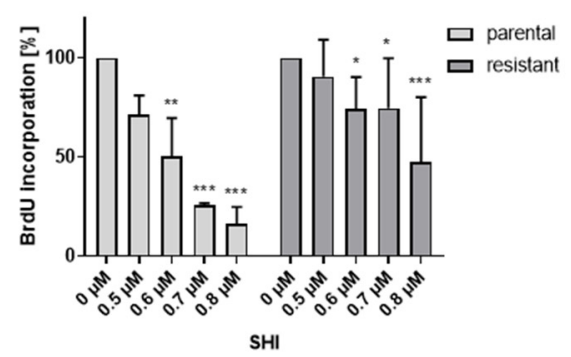

Figure 2. Cont. 


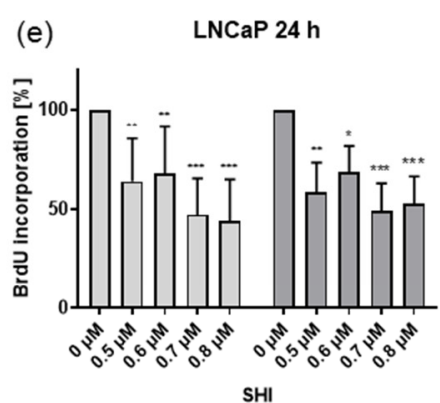

(g)

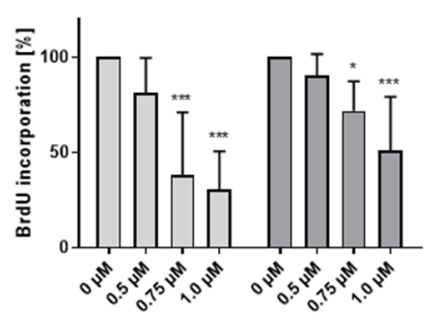

$\mathrm{SH}$

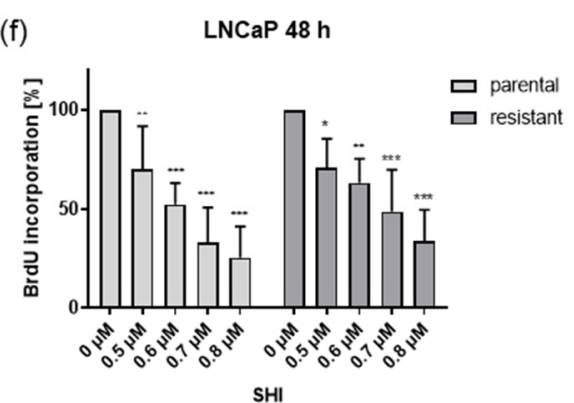

(h)

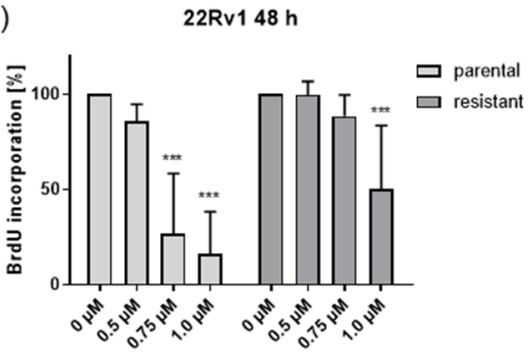

SHI

Figure 2. Tumor cell proliferation of parental and DX-resistant PC3 (a,b), DU145 (c,d), LNCaP $(\mathbf{e}, \mathbf{f})$, and $22 \operatorname{Rv} 1(\mathbf{g}, \mathbf{h})$ PCa cells incubated for $24 \mathrm{~h}$ and $48 \mathrm{~h}$ with SHI [0.5-0.8 $\mu \mathrm{M}](\mathbf{a}-\mathbf{f})$ or [0.5-1.0] (g,h). Untreated controls were set to $100 \%$. Error bars indicate standard deviation (SD). Significant difference to untreated control: ${ }^{*}=p \leq 0.05,{ }^{* *}=p \leq 0.01,{ }^{* * *}=p \leq 0.001 . n=3$.

2.3. Shikonin Induced Cell Cycle Arrest and Alterations in the Expression and Activity of Cell Cycle Regulating Proteins

Diminished tumor cell growth and proliferation after SHI treatment were partially due to impaired cell cycle progression (Figure 3). Exposure to $0.5 \mu \mathrm{M}$ SHI provoked a significant increase of cells in the G2/M phase in parental PC3 and DX-resistant DU145 cells. This was associated with a decrease of G0/G1 phase cells in parental PC3 and a reduction of S phase cells in DX-resistant DU145 (Figure 3a,d). DX-resistant 22Rv1 cells showed a significant elevation of the S phase after exposure to SHI, independent of the SHI concentration. This was accompanied by tendency by a decrease of cells in the G0/G1 and G2/M phases.

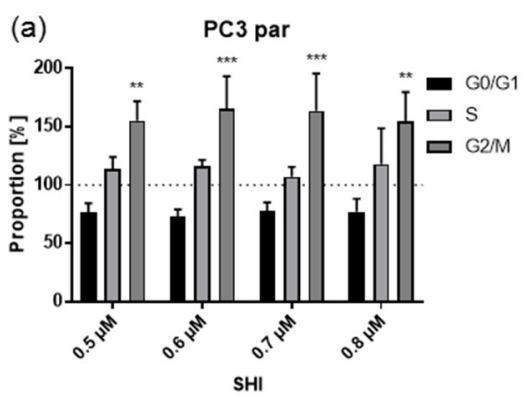

(c)

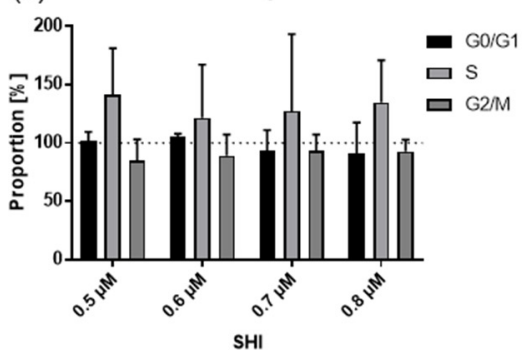

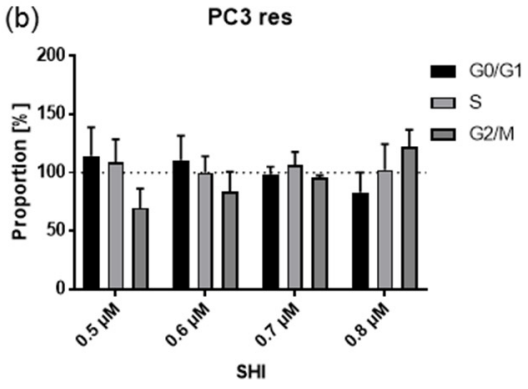

(d)

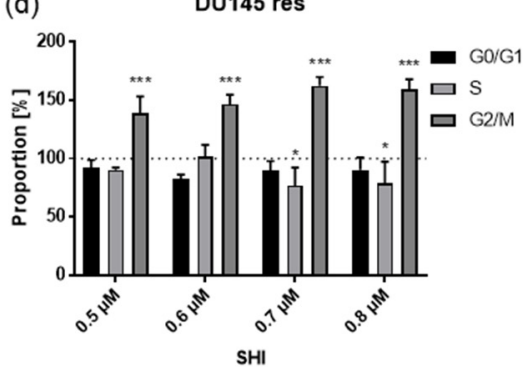

Figure 3. Cont. 

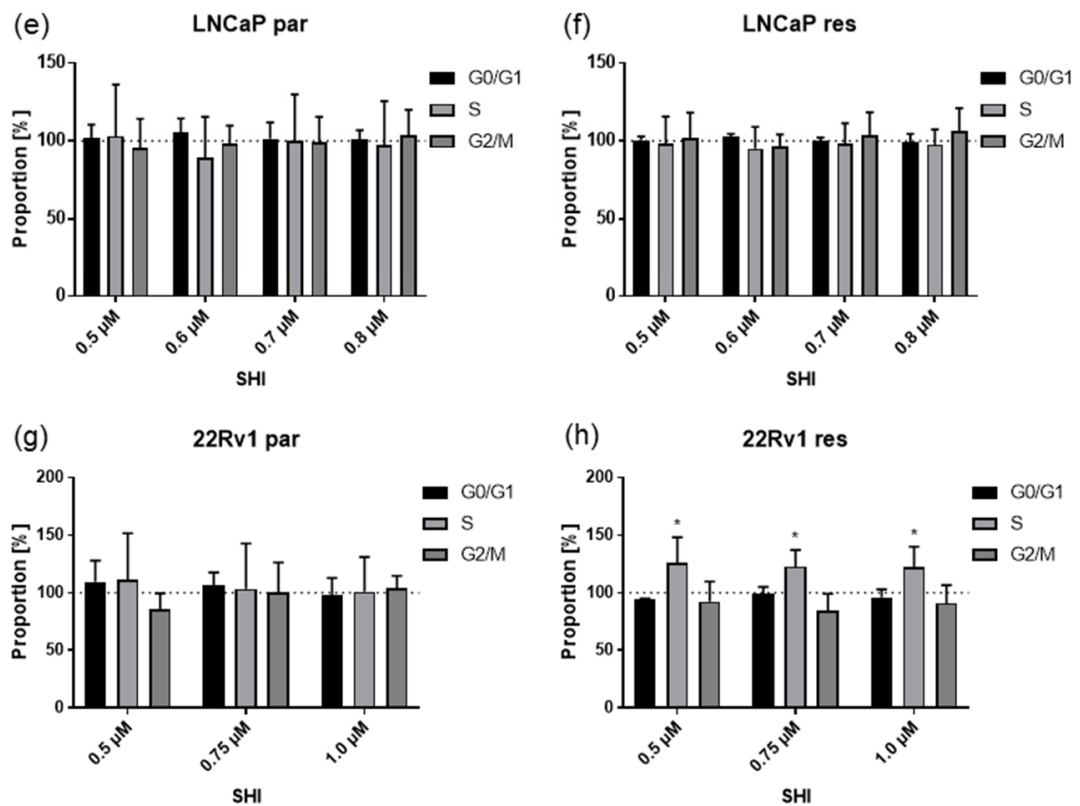

Figure 3. Distribution in the cell cycle phases: Proportion of parental (par) and DX-resistant (res) PCa cells, PC3 (a,b), DU145 (c,d), LNCaP (e,f), and 22Rv1 (g,h), in the G0/G1, S, and G2/M phases after $48 \mathrm{~h}$ treatment with SHI [0.5-0.8 $\mu \mathrm{M}](\mathbf{a}-\mathbf{f})$ and SHI [0.5-1.0 $\mu \mathrm{M}](\mathbf{g}, \mathbf{h})$. Untreated cells served as controls (dotted line; set to $100 \%$ ). Error bars indicate standard deviation (SD). Significant difference to untreated control: ${ }^{*}=p \leq 0.05,{ }^{* *}=p \leq 0.01,{ }^{* * *}=p \leq 0.001 . n=3$.

DX-resistant PC3, parental DU145, parental 22Rv1 cells, as well as parental and DXresistant LNCaP cells showed no significant changes in cell cycle progression after SHI exposure (Figure $3 b-g$ ). This indicates that other mechanisms are responsible for the observed inhibition of tumor cell growth and proliferation in these PCa cells.

As exposure to SHI revealed the strongest effects on the cell cycle progression in PC3 and DU145 cells, the expression and activity of cell cycle regulating proteins in these cell lines were evaluated. Indeed, modulation of the cell cycle phases was accompanied by significant alteration in the cell cycle regulating proteins (Figures 4-6, and Figures S1 and S2). Exposure to SHI resulted in a significant accumulation of p21 in parental but not in DXresistant PC3 cells (Figures 4 and 5a, and Figure S1a). In addition, there was a significant decrease of p27 in parental cells, whereas DX-resistant cells showed by tendency an increase (Figures 4 and 5b, and Figure S1b). Cyclin A, B and Cyclin-dependent kinase (CDK) 1, essential for G2/M phase [39], were significantly reduced by SHI in both parental and DX-resistant PC3 cells (Figures 4 and $5 c, d, g$, and Figure S1c,d,g). Furthermore, together with Cyclin $\mathrm{A}$, the expression of $\mathrm{CDK} 2$, both responsible for regulating $\mathrm{S}$ phase progression [40], was significantly reduced by exposure to SHI (Figures 4 and 5f,g, and Figure S1f,g). The active, phosphorylated form of CDK2 was also significantly decreased after exposure to SHI (Figures 4 and 5h, and Figure S1h). Cyclin D1, involved in G0/G1 phase progression, was not affected (Figures 4 and 5e, and Figure S1e). In good accordance with the cell cycle arrest of DX-resistant DU145 cells in the G2/M phase, alterations in the expression and activity of cell cycle-regulating proteins were mainly seen in DX-resistant cells (Figures 4 and 6, and Figure S2). This included the proteins Cyclin B, CDK1, CDK2, and pCDK2 (Figures 4 and $6 \mathrm{~d}, \mathrm{f}-\mathrm{h}$, and Figure S2d,f-h). However, CDK1 and 2 protein levels were also significantly reduced in parental DU145 cells (Figures 4 and 6f,g, and Figure S2f,g). 
PC3

DU145

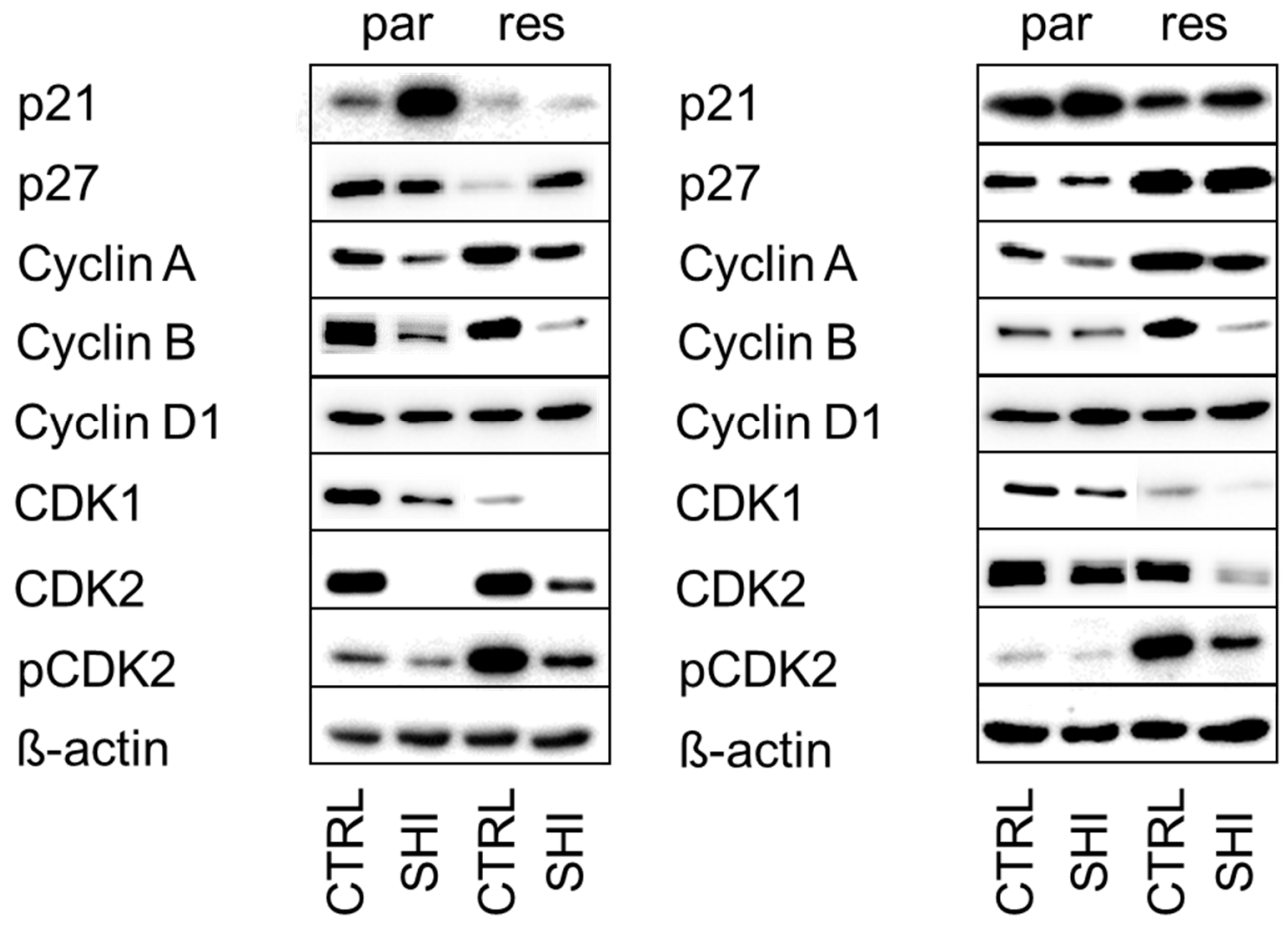

Figure 4. Protein expression profile of cell cycle regulating proteins: Representative Western blot images of cell cycle regulating proteins in parental (par) and DX-resistant (res) PC3 (left panel) and DU145 (right panel) cells after 48 h exposure to SHI $[0.5 \mu \mathrm{M}]$.

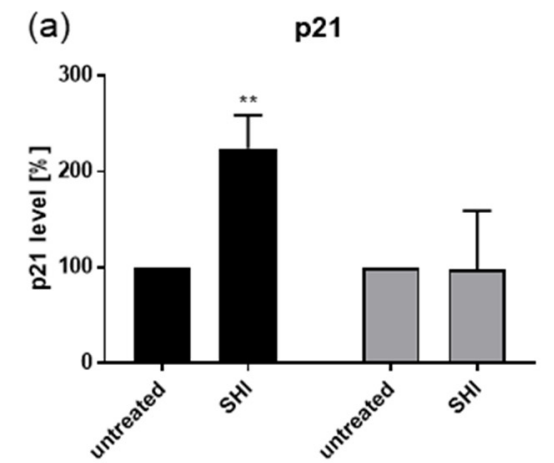

(c)

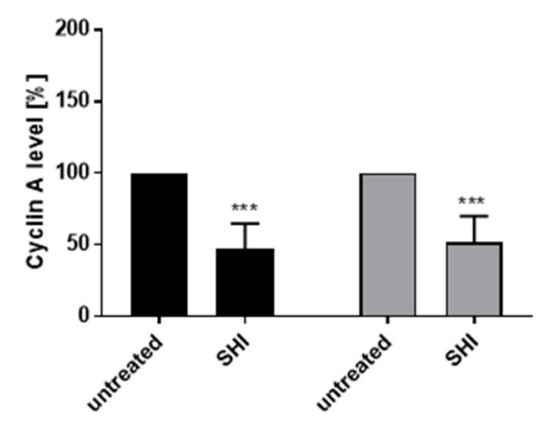

(b) p27

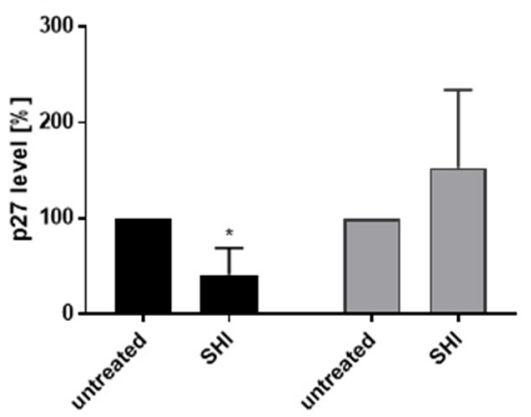

(d) Cyclin B

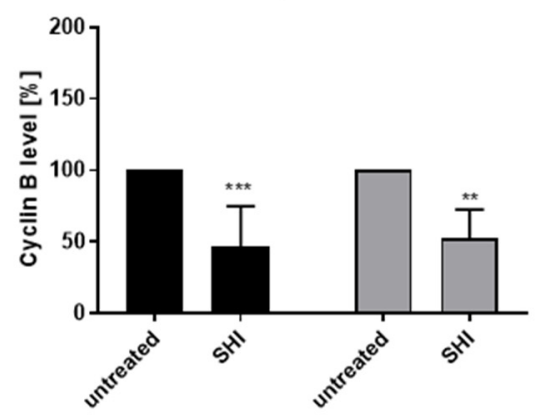

Figure 5. Cont. 
(e)

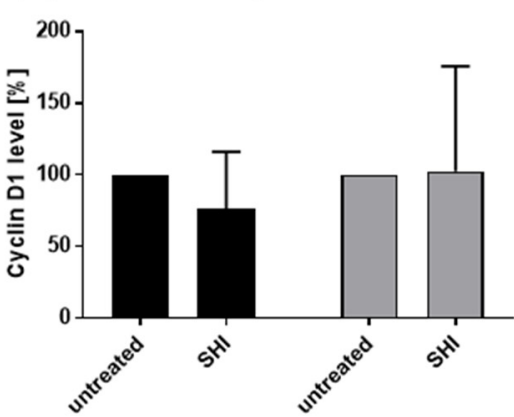

(g)

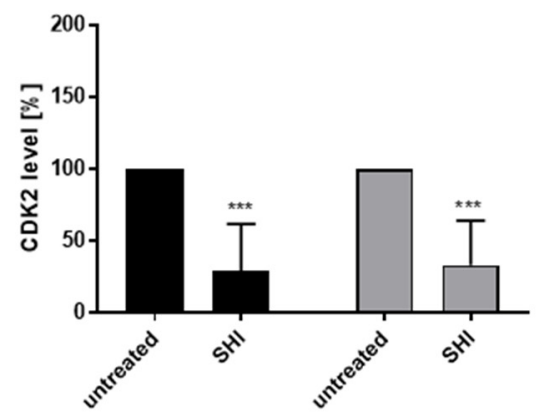

(f)

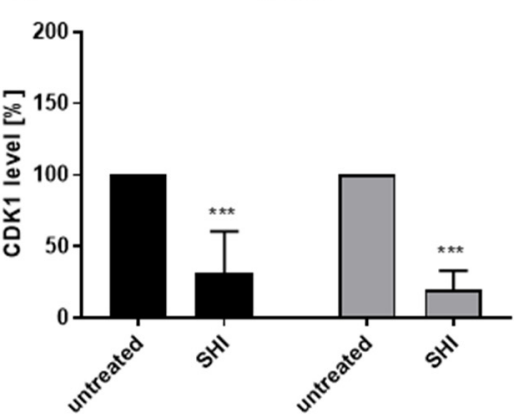

(h)

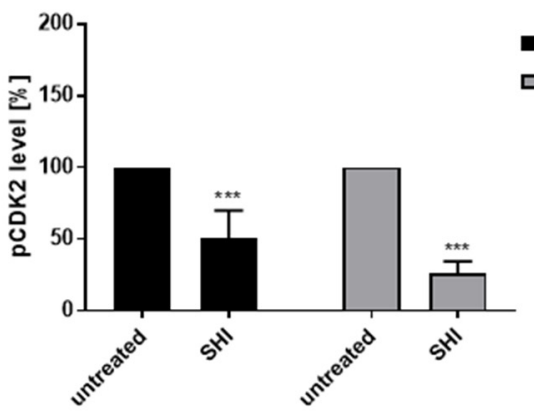

Figure 5. Protein expression profile of cell cycle regulating proteins: Pixel density analysis (Western blot) of the cell cycle regulating proteins p21 (a), p27 (b), Cyclin A (c), Cyclin B (d), Cyclin D1 (e), CDK1 (f), CDK2 (g), and pCDK2 (h) in parental and DX-resistant PC3 cells after $48 \mathrm{~h}$ exposure to SHI [0.5 $\mu \mathrm{M}]$, compared to untreated controls (set to 100\%). Each protein analysis was accompanied and normalized by a housekeeping protein. Error bars indicate standard deviation (SD). Significant difference to untreated control: ${ }^{*}=p \leq 0.05,{ }^{* *}=p \leq 0.01,{ }^{* * *}=p \leq 0.001 . n=3$. For detailed information regarding the Western blots, see Figure S1a-h.

(a)

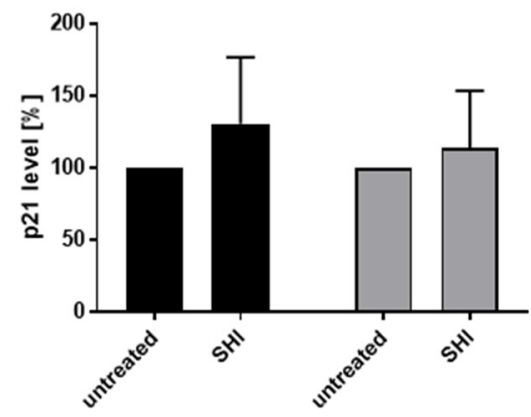

(c)

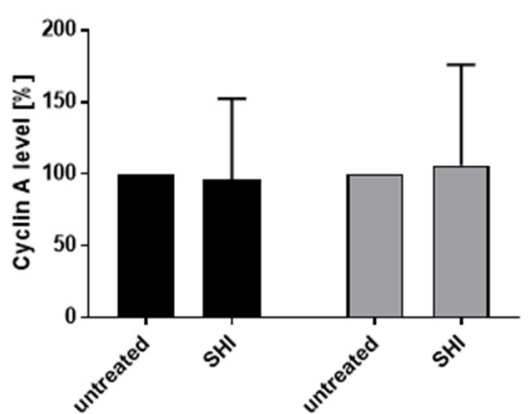

(b)

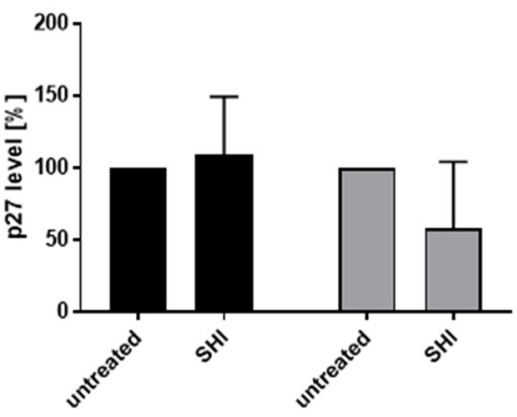

(d)

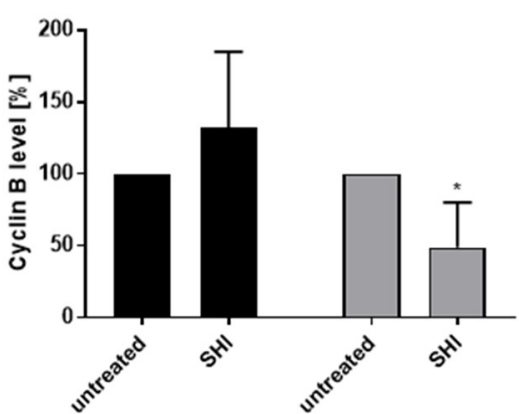

Figure 6. Cont. 
(e)

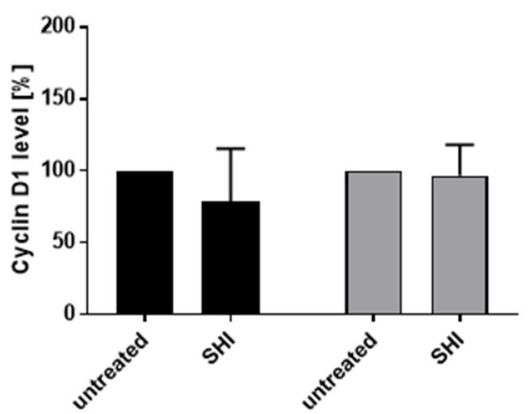

(g)

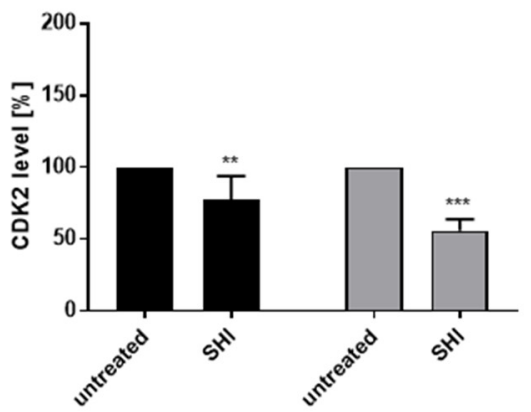

(f)

CDK1

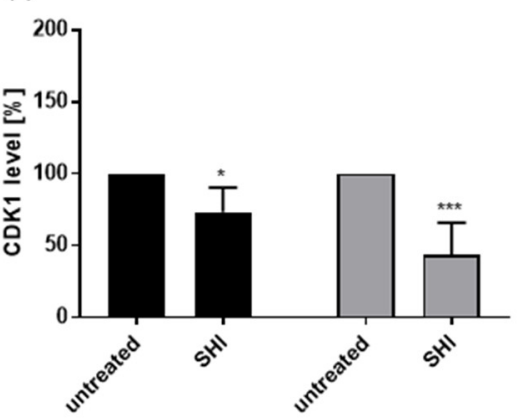

(h)

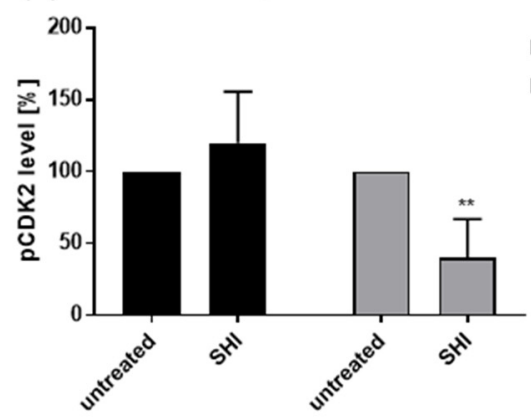

Figure 6. Protein expression profile of cell cycle regulating proteins: Pixel density analysis (Western blot) of the cell cycle regulating proteins p21 (a), p27 (b), Cyclin A (c), Cyclin B (d), Cyclin D1 (e), CDK1 (f), CDK2 (g), and pCDK2 (h) in parental and DX-resistant DU145 cells after 48 h exposure to SHI [0.5 $\mu \mathrm{M}]$, compared to untreated controls (set to 100\%). Each protein analysis was accompanied and normalized by a housekeeping protein. Error bars indicate standard deviation (SD). Significant difference to untreated control: ${ }^{*}=p \leq 0.05,{ }^{* *}=p \leq 0.01,{ }^{* * *}=p \leq 0.001 . n=3$. For detailed information regarding the Western blots, see Figure S2a-h.

\subsection{Shikonin Induced Cell Death}

Exposure to SHI dose-dependently resulted in an accumulation of apoptotic events in parental and DX-resistant PC3, and DU145 cells (Figure 7a,b). 22Rv1 cells displayed less pronounced cell death (Figure 7d). No apoptosis was detectable in parental LNCaP cells, and only applying a higher concentration of $0.7 \mu \mathrm{M}$ SHI or more contributed to apoptosis in the DX-resistant LNCaP cells (Figure 7c). Consequently, other antitumor effects of SHI must be responsible for the observed inhibition of growth and proliferation. Necrotic events were not apparent in the PCa cells.

Due to the low sensitivity of the 22Rv1 cell lines to SHI, further investigation was directed towards parental and DX-resistant PC3, DU145, and LNCaP cells. As a caspasedependent cell death could account for the growth inhibition induced by SHI, cells were exposed to zVAD, a multi-caspase inhibitor. However, in combination with SHI, zVAD did not influence the growth of parental and DX-resistant PC3, DU145, and LNCaP cells (Figure 8a-f), indicating a caspase-independent cell death induction. Parental DU145 cells treated with $12.5 \mathrm{nM}$ DX were used as a positive control, as DU145 has been shown to respond with a caspase-dependent apoptosis initiation after DX application [41]. In fact, combined treatment with DX and zVAD led to a significant recovery in tumor cell growth (Figure 8g). No changes in the protein expression of PARP or caspase 3 were apparent after SHI exposure, neither in parental nor in DX-resistant DU145 cells (Figure 8h,i and Figures S3 and S4), further corroborating the hypothesis of a caspase-independent cell death. Notably, the expression of caspase 8 significantly decreased after exposure to SHI (Figure $8 \mathrm{j}$ and Figure S5), indicating a caspase-independent cell death induction, such as necroptosis. 
(a)

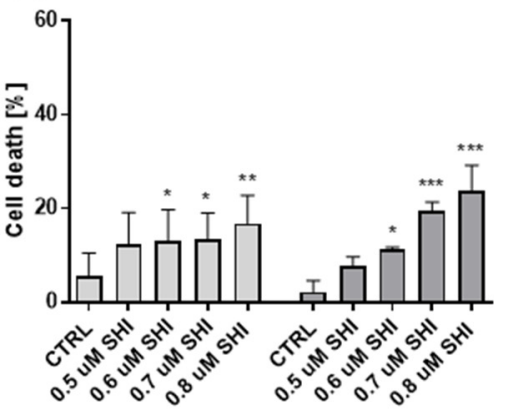

(c)

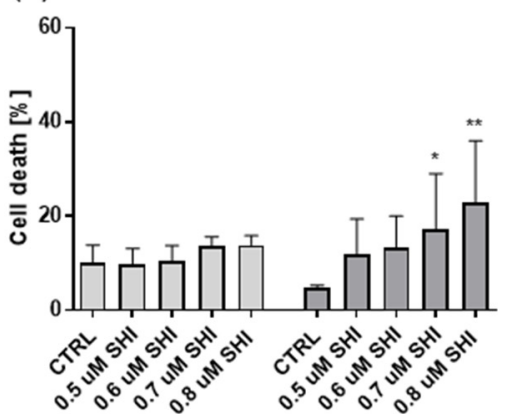

(b) DU145

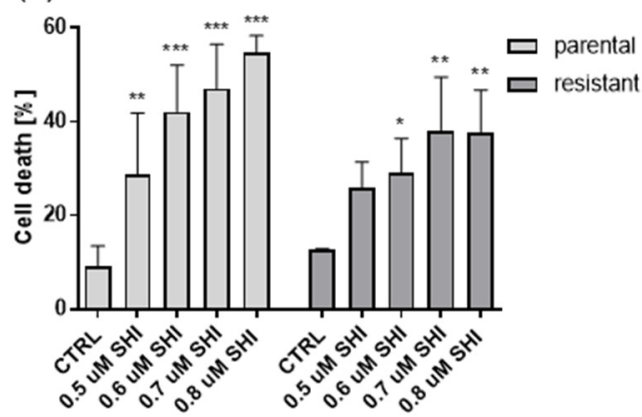

(d)

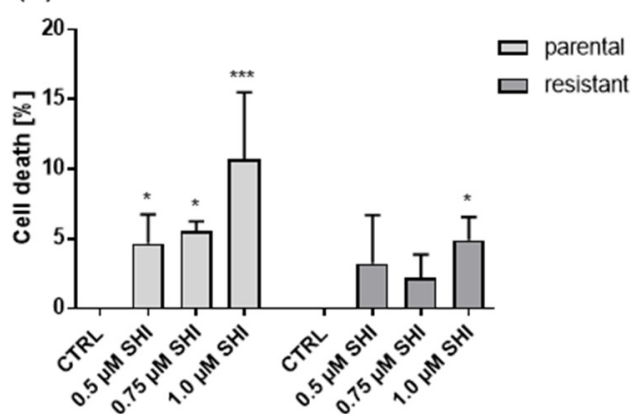

Figure 7. Cell death events: Percent of cell death in parental and DX-resistant PC3 (a), DU145 (b), LNCaP (c), and 22Rv1 (d) cells treated for $48 \mathrm{~h}$ with $0.5-0.8 \mu \mathrm{M} \mathrm{SHI}(\mathbf{a}-\mathbf{c})$ or $0.5-1.0 \mu \mathrm{M} \mathrm{SHI}(\mathbf{d})$, compared to the untreated controls. Error bars indicate standard deviation (SD). Significant difference to untreated control: ${ }^{*}=p \leq 0.05,{ }^{* *}=p \leq 0.01,{ }^{* * *}=p \leq 0.001 . n=3$.
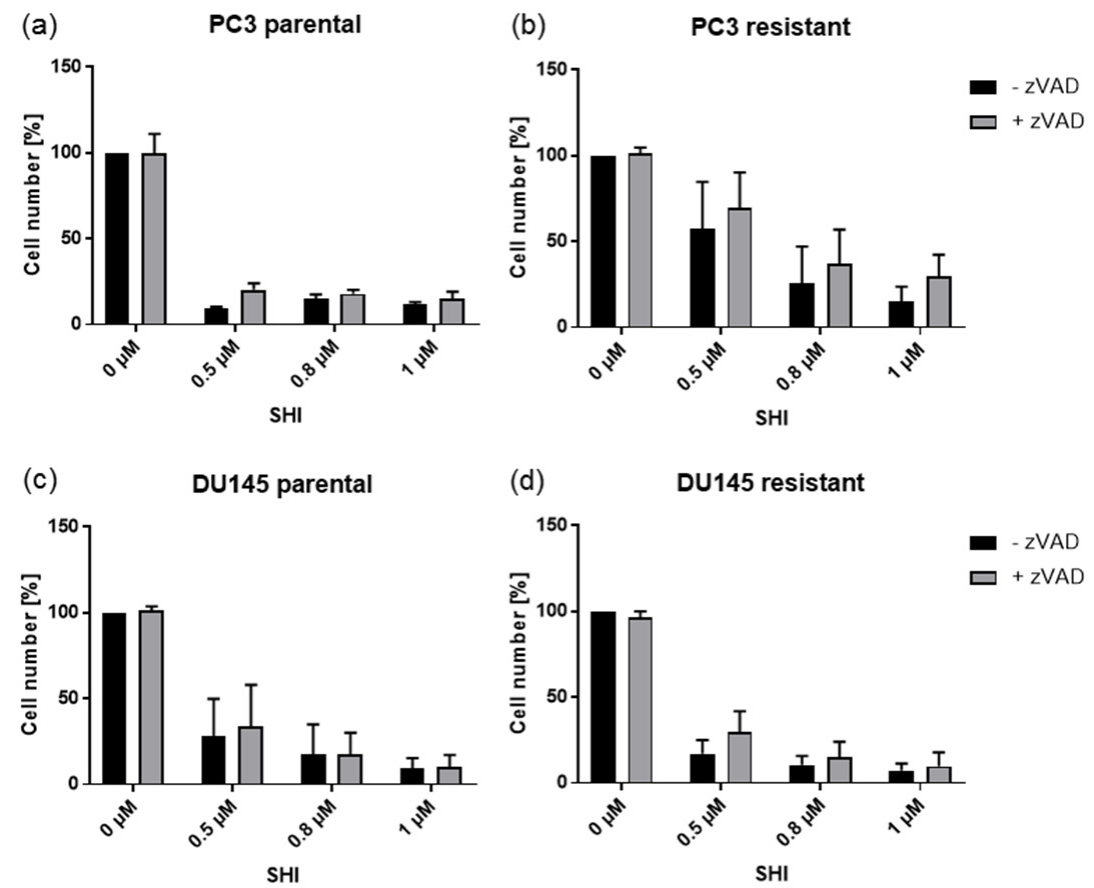

Figure 8. Cont. 

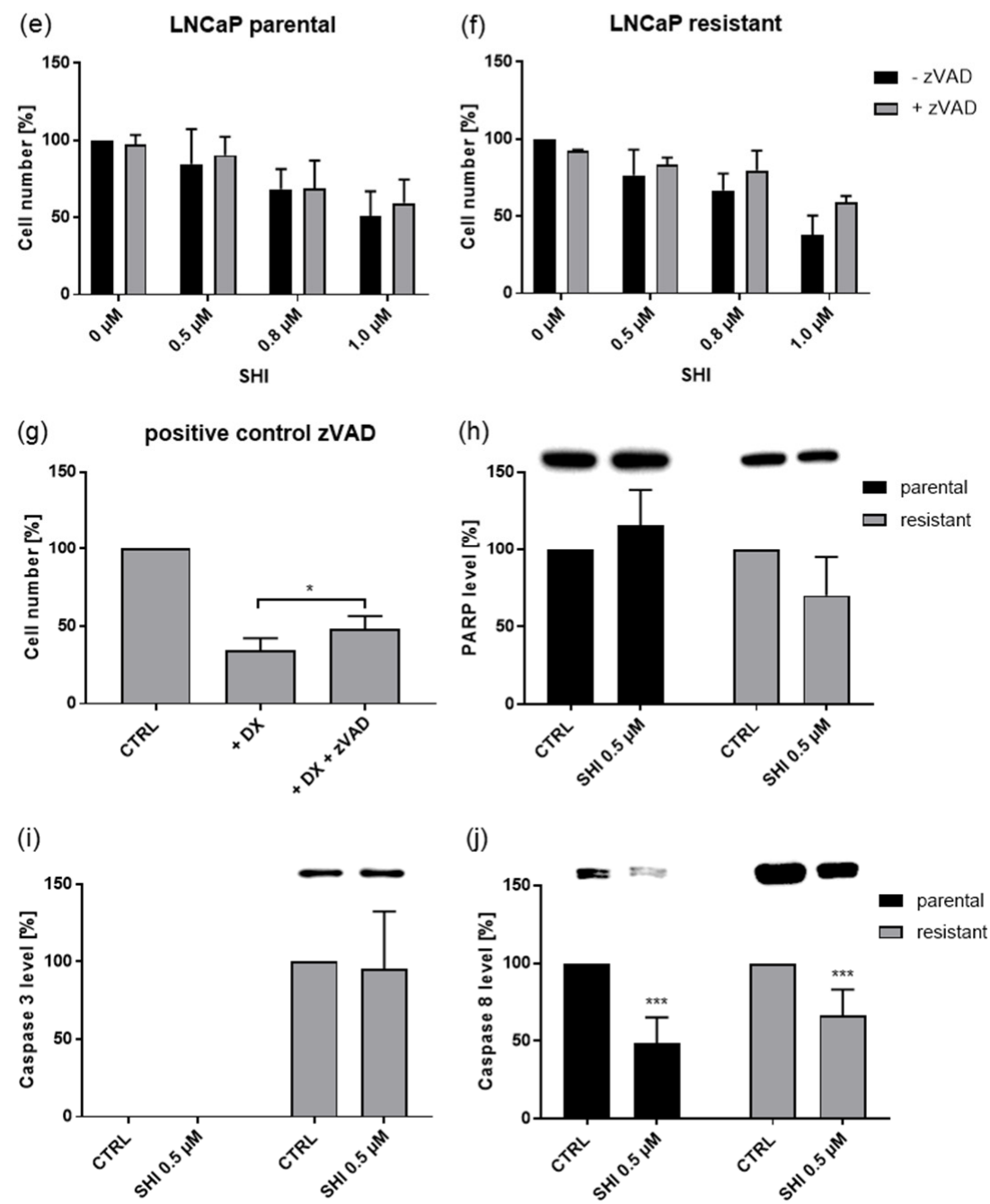

Figure 8. Caspase-dependent cell death: Cell growth of parental and DX-resistant PC 3 and DU145 cells treated for $48 \mathrm{~h}$ with SHI [0.5, 0.8, $1.0 \mu \mathrm{M}]$ and the multi-caspase inhibitor zVAD [20 $\mu \mathrm{M}](\mathbf{a}-\mathbf{f})$. SHI mono-treated and untreated (set to $100 \%$ ) cells served as controls. Parental DU145 cells treated with $12.5 \mathrm{nM}$ DX alone or in combination with $20 \mu \mathrm{M} \mathrm{zVAD}$ were used as a positive control to confirm zVAD activity (g). Error bars indicate standard deviation (SD). Significant difference compared to untreated controls, except for asterisk brackets indicating a significant difference between untreated and zVAD treated cells: ${ }^{*}=p \leq 0.05$. $n=3(\mathbf{a}-\mathbf{g})$. Protein expression of PARP $(\mathbf{h})$, caspase 3 (i), and caspase 8 (j) in parental and DX-resistant DU145 cells after 24 h exposure to $0.5 \mu \mathrm{M} \mathrm{SHI}$ : Representative Western blot images and pixel density analysis. Protein analysis was accompanied and normalized by a total protein control. Untreated cells served as controls (set to $100 \%$ ). Error bars indicate standard deviation (SD). Significant difference to untreated control: ${ }^{* * *}=p \leq 0.001 . n=3$. For detailed information regarding the Western blots, see Figures S3-S5.

\subsection{Shikonin Induced Necroptotic Effects}

Necroptosis is a caspase-independent cell death and necrostatin- 1 inhibits the activity of RIP1 and blocks the necroptosis pathway. As SHI induced necroptosis in various tumors $[28,30,32,34]$, necrostatin-1 was applied to determine whether SHI also has an impact on PCa tumor cell growth. SHI application significantly reduced growth in all cell lines (Figure $9 \mathrm{a}-\mathrm{f}$ ). Combined administration of $0.5-1.0 \mu \mathrm{M}$ SHI and $80 \mu \mathrm{M}$ necrostatin-1 resulted in a reversal of SHI's antigrowth effect in all parental and DX-resistant PCa cell lines, leading to cell growth comparable to the untreated controls (Figure 9a-f).

Representative for the tested PCa cell lines, PC 3 and DU145 cells showed an increase in pRIP1 and/or pRIP3 activation after exposure to SHI (Figure 10b,d,g,i and Figure S6b,d,g,i). 
In parental PC3, pRIP1 and pRIP3 were significantly activated by SHI, whereas additional application of necrostatin-1 reversed this activation (Figure 10b and Figure S6b). DXresistant PC3 cells revealed no effect on pRIP1 after exposure to SHI but displayed by tendency an elevation of pRIP3, compared to the SHI-untreated controls (Figure 10d and Figure S6d). Again, combined treatment with SHI and necrostatin-1 counteracted this activation and led to a significant decrease of pRIP1 and pRIP3, compared to the SHItreated cells. In the DU145 cells both parental and stronger DX-resistant DU145 cells showed a significant upregulation of pRIP1 by SHI (Figure 10g and Figure S6g). Addition of necrostatin-1 to SHI in parental and DX-resistant DU145 cells significantly abolished RIP1 phosphorylation. pRIP3 was also significantly amplified after SHI application in parental DU145 cells (Figure 10i and Figure S6i). As before, phosphorylation was abrogated by combining SHI with necrostatin-1. In contrast, the expression of total RIP1, RIP3, and MLKL was not significantly affected by SHI (Figure 10a,c,e,f,h,j and Figure S6a,c,e,f,h, , ), and pMLKL was not detectable in the PC3 and DU145 cells. Combined application to SHI and necrostatin-1 significantly reduced the total amount of RIP3 in parental PC3 (Figure 10c and Figure S6c) and of RIP1 in DX-resistant DU145 (Figure 10f and Figure S6f).

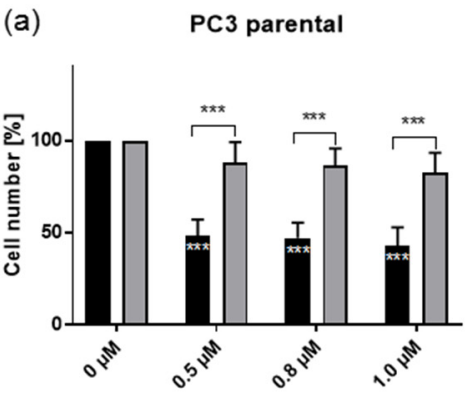

(c)

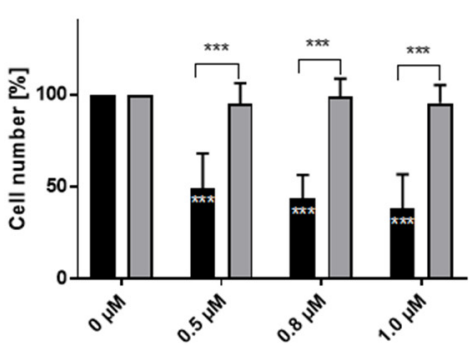

(e)

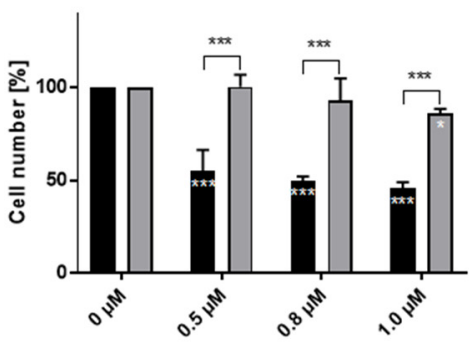

(b)

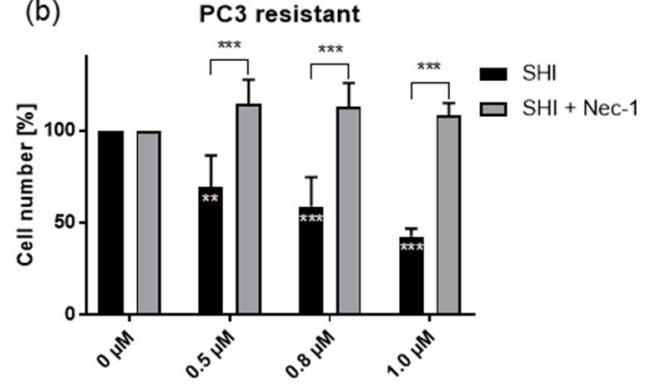

(d)

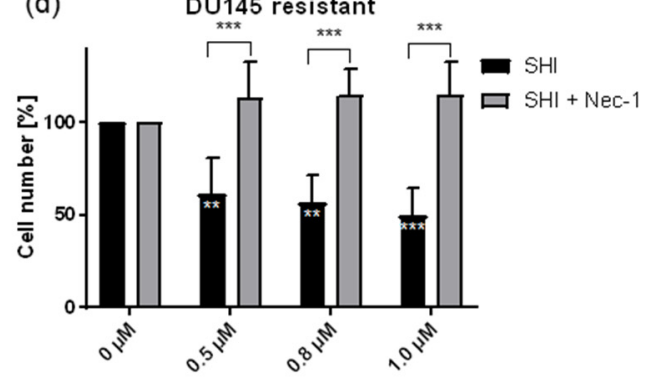

(f)

LNCaP resistant

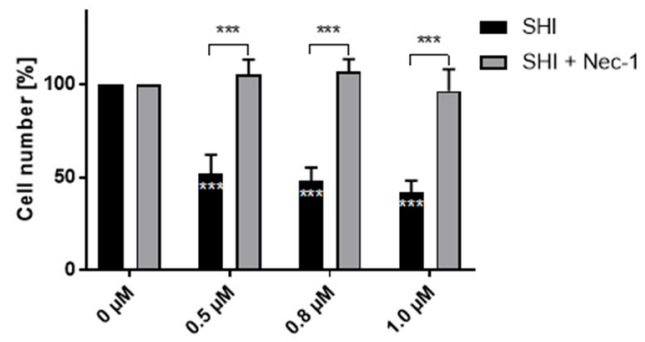

Figure 9. Necroptosis in PCa cells: Necroptosis induction of parental and DX-resistant PC3 (a,b), DU145 (c,d) and LNCaP (e,f) cells treated for $24 \mathrm{~h}$ with $0.5,0.8$, and $1.0 \mu \mathrm{M} \mathrm{SHI}$ and $80 \mu \mathrm{M}$ necrostatin1 (Nec-1). SHI mono-treated and untreated (set to 100\%) cells served as controls. Error bars indicate standard deviation (SD). Significant difference, compared to untreated controls, except for asterisk brackets indicating a significant difference between Nec-1 untreated and treated cells: ${ }^{* * *}=p \leq 0.001$. $n=5$.

In addition, administration of $0.5 \mu \mathrm{M} \mathrm{SHI}$ resulted in a significant decrease of the GSHcontent in parental and DX-resistant DU145 cells (Figure 11), indicating ROS generation. 

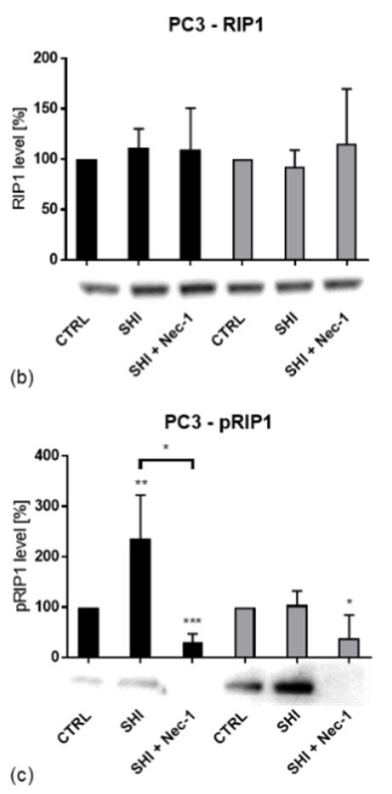

PC3 - RIP3
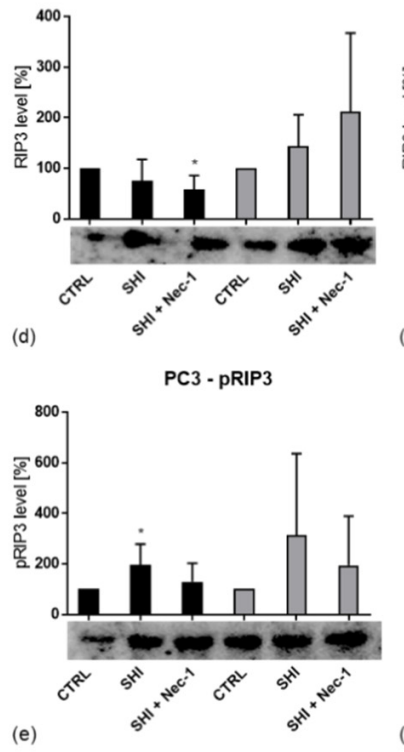

PC3 - MLKL

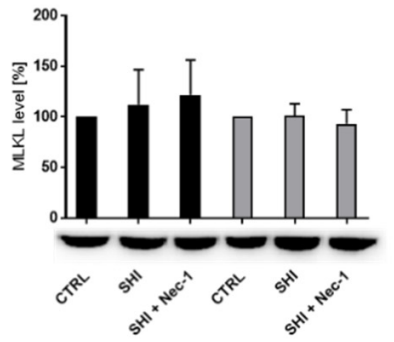

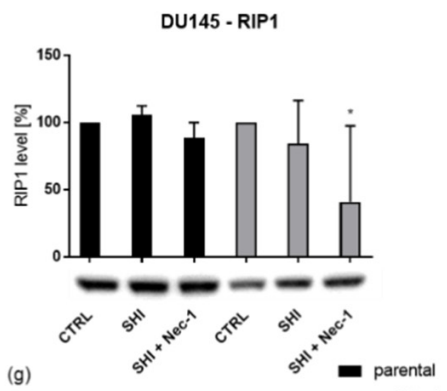
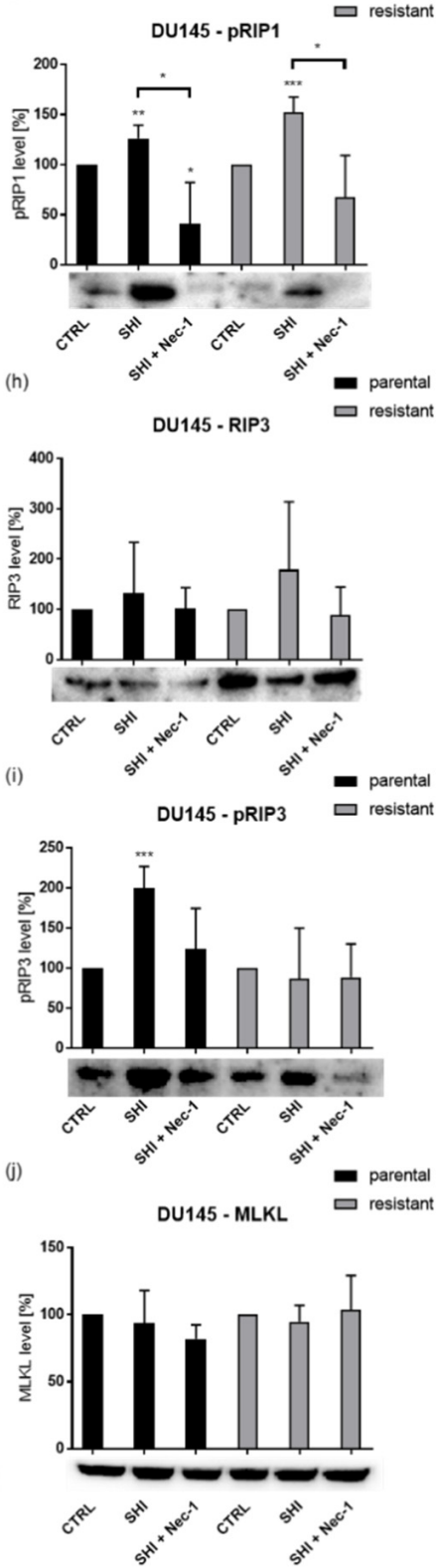

Figure 10. Expression and activity of necroptosis markers in PCa cells: Protein expression of RIP1 $(\mathbf{a}, \mathbf{f})$, pRIP1 $(\mathbf{b}, \mathbf{g}), \operatorname{RIP3}(\mathbf{c}, \mathbf{h}), \mathrm{pRIP3}(\mathbf{d}, \mathbf{i})$, and MLKL $(\mathbf{e}, \mathbf{j})$ in parental and DX-resistant PC3 (a-e) and DU145 (f-j) cells after $12 \mathrm{~h}$ exposure to $0.5 \mu \mathrm{M}$ SHI and $80 \mu \mathrm{M}$ necrostatin-1 (Nec-1). Representative Western blot images and pixel density analysis. Protein analysis was accompanied and normalized by a total protein control. Untreated cells served as controls (set to 100\%). Error bars indicate standard deviation (SD). Significant difference to untreated control: ${ }^{*}=p \leq 0.05,{ }^{* *}=p \leq 0.01, * * *=p \leq 0.001$. $n=3$. For detailed information regarding the Western blots, see Figure S6a-j. 
(a)

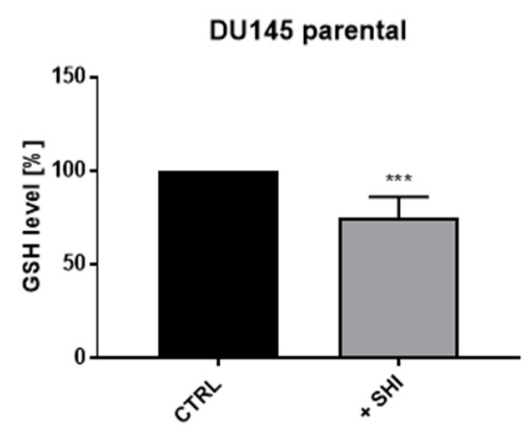

(b)

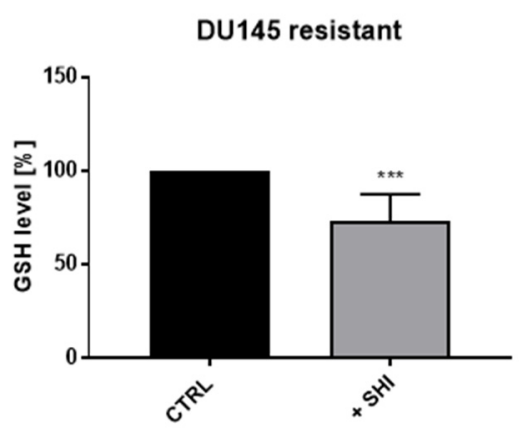

Figure 11. GSH content in DU145 cells: GSH was measured after $24 \mathrm{~h}$ exposure to $0.5 \mu \mathrm{M}$ SHI. Untreated cells served as controls (set to $100 \%$ ). Error bars indicate standard deviation (SD). Significant difference to untreated control: ${ }^{* *}=p \leq 0.001 . n=6$.

\subsection{Shikonin Showed No Effects on Metabolism}

SHI has been shown to directly influence mitochondrial activity [38] and serve as a specific pyruvate kinase M2 inhibitor [24]. Inhibiting this enzyme with SHI could therefore directly influence tumor cell metabolism. Basal oxygen consumption rate and extracellular acidification rate were comparable in parental and DX-resistant PCa cells. However, treatment with SHI resulted only in temporarily elevated mitochondrial respiration and decreased aerobic glycolysis in the DU145 cells, indicating transient enhanced oxidative phosphorylation in response to a stress stimulus (Figure S7).

\section{Discussion}

Prostate carcinoma is the most common malignant tumor in men. Currently, there is no curative therapy for advanced prostate carcinoma, and palliative treatment is most often the only open option. Conventional therapeutic approaches are intended to prolong progression-free survival but are limited in their effect and result in resistance, so that new treatment strategies are crucial. Addition of SHI is a possible treatment strategy, as in the current study it inhibited growth and reduced proliferation of four parental and DX-resistant PCa cell lines. In good accordance with this, SHI treatment in lung [42], gallbladder [43], esophagus [44], and breast cancer [45] has resulted in reduced growth in vitro. SHI has also shown in vivo growth inhibition of nasopharyngeal cancer [46] and melanoma [37]. Diminished growth with SHI has also been shown in therapy-sensitive PC3 and LNCaP cells [47] through inhibition of the AKT/mTOR signaling pathway. Exposure to $\mathrm{SHI}$ has been shown to restrict the growth of $\mathrm{LNCaP}$, and $22 \mathrm{Rv} 1$ cells by affecting the androgen receptor [48].

Growth and proliferation inhibition after treatment with $\mathrm{SHI}$ was associated with a cell cycle arrest of parental PC3 and DX-resistant DU145 cells in the G2/M phase, and an S-phase arrest in DX-resistant 22Rv1. Furthermore, in pancreatic, lung [25], breast [31], gastric cancer cells [26], and melanoma [49] the administration of SHI resulted in cell cycle arrest in the G2/M phase. In a study on therapy-sensitive PC3 and DU145 cells, SHI induced a shift to the G2/M phase [47]. However, data of cell cycle regulating proteins were missing.

In the current study, the SHI-initiated G2/M phase arrest in PC3 and DU145 cells was evident at the protein level. In parental and DX-resistant PC 3 cells, SHI induced a significant decrease in the cell cycle regulating proteins Cyclin A, Cyclin B, CDK1, and CDK2, which are responsible for G2/M phase progression, whereas an increase of p21 and a decrease of p27 was only apparent in parental PC 3 cells. Consistent with the cell cycle data, DX-resistant DU145 cells showed a stronger downregulation of Cyclin B, CDK1, and CDK2 by SHI, compared to the parental cells. In line with the current data on PCa cells, treatment of gastric cancer cells with SHI resulted in a G2/M phase arrest, associated with a reduction of cell cycle activating proteins and an increase in the cell cycle inhibitor p21 [26]. 
Reduced Cyclin B and increased p21, concomitant to a G2/M arrest after SHI application, have also been detected in melanoma cells [49]. Downregulation of p27 triggered cell cycle arrest in endothelial cells [50] and pancreas cancer cells [51], in connection with a tumor suppressor activity. As Cyclin B in complex with CDK1, mediates the transition from the G2 to M phase [52] the downregulation of Cyclin B by SHI may prevent the transition from the G2 to M phase. This may produce the cell cycle arrest in the parental and DX-resistant PCa cells observed here.

Aside from the cell cycle arrest in the G2/M phase, growth inhibition was accompanied by a significant apoptosis increase in all the PCa cell lines, except for LNCaP, where only a higher dose of SHI induced significant apoptotic effects in the DX-resistant cells. Necrotic events after SHI exposure were not detectable in the parental and DX-resistant PCa cells; thus, necrosis induction could not be responsible for SHI's growth inhibitory effect. In good accordance with the current apoptosis data, $\mathrm{SHI}$ induced apoptosis in various tumor entities. In esophageal cancer cells, apoptosis induction by SHI was a result of the specific inhibition of PKM2, leading to a loss of energy generation [53]. In contrast, in lung cancer cell lines the apoptosis induction by SHI has been attributed to the FOXO3a/EGR1/SIRT1 pathway [42]. In leukemia cells, SHI led to apoptosis, postulated to be associated with the inhibition of c-Myc [54]. Apoptosis could also be induced in gastric cancer cell lines via the mitochondrial caspase-dependent pathway, as shown by the multi-caspase inhibitor zVAD, which inhibits the antigrowth effect of SHI [27].

However, in the current study zVAD did not abolish the inhibitory effect of SHI on growth, indicating a caspase-independent induction of cell death. In fact, zVAD even significantly decreased the inhibitory effect of DX on DU145 cell growth. It is known that DX induces caspase-dependent apoptosis in DU145 cells [41]. However, in good accordance with the current SHI data regarding PCa, zVAD did not block the growth inhibitory effect of SHI in lung cancer cells [29]. Similar results have been obtained with osteosarcoma [55], and gastric cancer cells [28]. Here too, growth inhibition by SHI could not be reverted by zVAD, indicating an absence of caspase-dependent apoptosis. Indeed, exposure to SHI alone in bladder carcinoma [34] and osteosarcoma cells [55] had no impact on the expression of caspase 3. Accordingly, in the PCa cells the expression of caspase 3 was not altered by the application of $\mathrm{SHI}$, further corroborating the hypothesis of a caspase-independent apoptosis induction.

Notably, caspase 8 was significantly reduced in the PCa cells after exposure to SHI, suggesting a necroptosis induction, an apoptosis-related programmed cell death [32]. Necroptosis is a regulated cell death, but in contrast to "classic" apoptosis, which is known to be caspase 3-dependent, necroptosis is characterized by diminished caspase 8 expression and activity. Activated caspase 8 would lead to apoptosis induction. Inactivation and downregulation of caspase 8 plays a pivotal role in necroptosis, facilitating the formation of a necrosome complex, consisting of RIP1, RIP3, and MLKL. This complex leads to membrane permeabilization and finally to cell death.

Indeed, adding the necroptosis inhibitor necrostatin-1 resulted in a tumor cell growth equivalent to the untreated controls in all parental and DX-resistant PCa cells, including LNCaP. Accordingly, in gastric cancer cell lines, necrostatin-1 blocked the antitumor effect of SHI [56]. In lung cancer cells, administration of SHI and necrostatin-1 resulted in a significant reversion of SHI's inhibitory effect [29]. Notably, the combined treatment with SHI, necrostatin-1, and DX in the DX-resistant PC3 and DU145 cells displayed even increased growth beyond the growth of the SHI and necrostatin-1 untreated controls. Taxanes, such as DX, induced necroptosis in lung [57] and breast cancer [58,59]. Thus, at least in the DX-resistant PC3 and DU145 cells, necroptotic processes seem to be enhanced after the combined exposure to SHI and DX, which might indicate re-sensitivation of the DX-resistant PCa cells. Pancreatic cancer treatment with SHI and gemcitabine [28] as well as combined application of SHI and erlotinib to glioblastoma induced synergistic effects [60]. Furthermore, chronic administration of SHI with cisplatin or paclitaxel to different cancer cell lines prevented resistance induction [61]. These studies with SHI 
application to other tumor entities seem to further corroborate our hypothesis that SHI reactivates the necroptotic activity of DX.

RIP1 and RIP3 are critical proteins involved in necroptosis induction [32]. Consistent with this, S166 phosphorylation of RIP1, indicating induction of necroptotic signaling, was evident in parental PC3 and DU145 cells, as well as in DX-resistant DU145 and by tendency in PC3 cells after SHI treatment. Furthermore, in gastric cancer cell lines [28], glioma [62], and osteosarcoma cells [55] administration of SHI resulted in a significant increase of RIP1 and RIP3. In the parental PCa cells, pRIP1 facilitated phosphorylation of RIP3, a downstream effector of the necrosome complex. Elevated phosphorylation of RIP1 and RIP3 was reversed when necrostatin- 1 was added. pMLKL is another component of the necrosome complex downstream of RIP3 [63]. MLKL is recruited and phosphorylated by pRIP3, the next step in initiation of necroptosis. In the PCa cells, no pMLKL was detectable after exposure to SHI, as a downstream target probably occurring after the chosen $12 \mathrm{~h}$ incubation. The application period might also explain why the parental $\mathrm{PCa}$ cells showed stronger effects in the phosphorylation of RIP3 than the DX-resistant cells, although necroptotic effects were more pronounced - but at a later time point. However, after $12 \mathrm{~h}$ SHI treatment, pRIP1 and pRIP3 were upregulated in the parental and by tendency in the DX-resistant PCa cells, further confirming the postulated functional role of $\mathrm{SHI}$ in necroptosis initialization.

The GSH-content was also significantly diminished after SHI application in the parental and DX-resistant PCa cells, indicating ROS generation. Necroptosis induction has also been shown to be accompanied by increased ROS levels in nasopharyngeal carcinoma cells [46]. SHI-induced GSH depletion and intracellular ROS increase in tumor cells has been demonstrated to be RIP1- and RIP3-mediated [62,64] as well, further confirming that $\mathrm{SHI}$ induces necroptosis, as observed in the current investigation.

Therefore, the measured "apoptotic" effects mainly seem to be due to necroptosis. However, the SHI treatment of LNCaP cells revealed only marginal apoptosis, indicating another mechanism. In contrast to the other tested PCa cells, LNCaP cells are androgen receptor (AR)-positive and androgen-sensitive [65,66]. As SHI inhibited AR [48], which prevents cell death processes through the tumor necrosis factor- $\alpha$ (TNF- $\alpha$ ) [67], this inhibition might play a crucial role in the necroptosis induction in LNCaP. Notably, TNF- $\alpha$ is involved in necroptotic processes $[68,69]$. However, the role of TNF- $\alpha$ in LNCaP cells requires further investigation.

SHI has also been described to directly or indirectly influence the metabolism of cancer cells $[38,70]$. In the current investigation, SHI only induced a significant short-term increase in OCR in the DU145 cells, partially accompanied by decreased glycolysis. This short-lasting metabolic shift towards mitochondrial respiration might indicate a temporary avoidance of apoptosis induction, as has previously been hypothesized [71]. Necroptosis induction by SHI has been postulated to overcome apoptosis resistance [34,72]. Indeed, SHI-induced necroptosis prevented tumor escape, resulting in significant growth inhibition of the PCa cells.

The androgen-insensitive PC3 and DU145 cells showed the highest sensitivity to SHI, whereas LNCaP exhibited the lowest sensitivity. However, in all four parental and DX-resistant PCa cell lines investigated here, $\mathrm{SHI}$ induced significant growth inhibition and necroptosis, accompanied by corresponding alterations in cell cycle and cell death regulating proteins. Further investigations in vitro and in vivo are necessary to verify this in vitro data.

\section{Materials and Methods}

\subsection{Cell Cultures}

Prostate cancer cell lines PC3, DU145, LNCaP, and 22Rv1 were obtained from the German Collection of Microorganisms and Cell Cultures (DSMZ). The DX-resistant sublines were derived from the Resistant Cancer Cell Line (RCCL) collection (https:/ / research.kent. ac.uk/industrial-biotechnology-centre/the-resistant-cancer-cell-line-rccl-collection/) [73]. 
LNCaP cells were grown and subcultured in Iscove Basal medium (Biochrom $\mathrm{GmbH}$, Berlin, Germany), and PC3, DU145, and 22Rv1 cells were grown in RPMI-1640 medium (Gibco, Thermo Fisher Scientific, Darmstadt, Germany). Media were supplemented with $10 \%$ fetal calf serum (FCS) (Gibco, Thermo Fisher Scientific, Darmstadt, Germany), 1\% glutamax (Gibco, Thermo Fisher Scientific, Darmstadt, Germany), and 1\% Anti/Anti (Gibco, Thermo Fisher Scientific, Darmstadt, Germany). Twenty micromolar HEPES buffer (Sigma-Aldrich, Darmstadt, Germany) was added to the RPMI-1640 medium. Tumor cells were cultivated in a humidified, $5 \% \mathrm{CO}_{2}$ incubator.

\subsection{Resistance Induction and Application of Docetaxel and Shikonin}

DX-resistant sublines were established by continuous exposure to stepwise increasing drug concentrations as previously described [74]. The DX-resistant tumor cells were exposed to $12.5 \mathrm{nM}$ DX (Sigma-Aldrich, Darmstadt, Germany) three times a week. Therapysensitive (parental) PCa cells served as controls. Shikonin (SHI) (Sigma-Aldrich, Darmstadt, Germany) was applied for 24,48 , or $72 \mathrm{~h}$ at a concentration of $0.1-1.5 \mu \mathrm{M}$. Controls (parental and DX-resistant) remained SHI-untreated. The IC50 (half-maximal inhibitory concentration) of SHI in parental and DX-resistant PCa cells was evaluated using the $72 \mathrm{~h}$ growth data at a concentration of 0.1-1.5 $\mu \mathrm{M}$ SHI. To evaluate possible toxic effects of DX and/or SHI, cell viability was determined parallel to experimentation by testing aliquoted cells with trypan blue (Sigma-Aldrich, Darmstadt, Germany). Only viable cells were used for growth and proliferation assays (see Sections 4.3 and 4.4).

\subsection{Tumor Cell Growth}

Cell growth was assessed using 3-(4,5-dimethylthiazol- 2-yl)-2,5-diphenyltetrazolium bromide (MTT) dye. PCa cells $\left(50 \mu \mathrm{L}, 1 \times 10^{5}\right.$ cells $\left./ \mathrm{mL}\right)$ were seeded into 96-well plates. After 24, 48, and 72 h, $10 \mu \mathrm{L}$ MTT (0.5 mg/mL) (Sigma-Aldrich, Darmstadt, Germany) was added for $4 \mathrm{~h}$. Cells were then lysed in $100 \mu \mathrm{L}$ solubilization buffer containing $10 \%$ SDS in $0.01 \mathrm{M} \mathrm{HCl}$. The plates were subsequently incubated overnight at $37^{\circ} \mathrm{C}, 5 \% \mathrm{CO}_{2}$. Absorbance at $570 \mathrm{~nm}$ was determined for each well using a multimode microplate-reader (Tecan, Spark 10 M, Crailsheim, Germany). After subtracting background absorbance and offsetting with a standard curve, results were expressed as mean cell number. To illustrate dose-response kinetics, the mean cell number after $24 \mathrm{~h}$ incubation was set to $100 \%$. Each experiment was done in triplicate.

\subsection{Proliferation}

Cell proliferation was measured using a BrdU (bromodeoxyuridine/5-bromo-2'deoxyuridine) cell proliferation enzyme-linked immunosorbent assay (ELISA) kit (Calbiochem/Merck Biosciences, Darmstadt, Germany). Tumor cells $\left(50 \mu \mathrm{L}, 1 \times 10^{5}\right.$ cells $\left./ \mathrm{mL}\right)$, seeded into 96-well plates, were incubated with $20 \mu \mathrm{L}$ BrdU-labeling solution per well for $24 \mathrm{~h}$, and fixed and stained using anti-BrdU mAb according to the manufacturer's protocol. Absorbance was measured at $450 \mathrm{~nm}$ using a multimode microplate-reader (Tecan, Spark $10 \mathrm{M}$, Crailsheim, Germany). Values were presented as percentage compared to untreated controls set to $100 \%$.

\subsection{Cell Cycle Phase Distribution}

For cell cycle analysis, cell cultures were grown to sub-confluency. A total of $1 \times 10^{6}$ cells was stained with propidium iodide $(50 \mu \mathrm{g} / \mathrm{mL}$ ) (Invitrogen, Thermo Fisher Scientific, Darmstadt, Germany) and then subjected to flow cytometry (Fortessa X20, BD Biosciences, Heidelberg, Germany). Ten-thousand events were collected from each sample. Data acquisition was carried out using DIVA software (BD Biosciences, Heidelberg, Germany), and cell cycle distribution was analyzed by ModFit LT 5.0 software (Verity Software House, Topsham, ME, USA). The number of cells in the G0/G1, S, or G2/M phases was expressed as a percentage. Untreated cells served as controls (dotted line; set to 100\%). 


\subsection{Western Blot Analysis of Cell Cycle and Cell Death Regulating Proteins}

To explore the expression and activity of cell cycle and cell death regulating proteins, Western blot analysis was performed. Tumor cell lysates (50 $\mu \mathrm{g}$ ) were applied to $10 \%$ or $12 \%$ polyacrylamide gels and separated for $10 \mathrm{~min}$ at $80 \mathrm{~V}$ and for $\sim 60-90 \mathrm{~min}$ at $120 \mathrm{~V}$. The proteins were then transferred to nitrocellulose membranes $(1 \mathrm{~h}, 100 \mathrm{~V})$. After blocking with $10 \%$ non-fat dry milk for $1 \mathrm{~h}$, the membranes were incubated overnight with the following primary antibodies directed against cell cycle proteins: p21 (Rabbit IgG, clone 12D1, dilution 1:1000, Cell Signaling, Frankfurt am Main, Germany), p27 (Mouse IgG ${ }_{1}$, clone 57/Kip1, dilution 1:500, BD Biosciences, Heidelberg, Germany), Cyclin A (Mouse $\mathrm{IgG}_{1}$, clone 25, dilution 1:500, BD Biosciences, Heidelberg, Germany), Cyclin B (Mouse $\mathrm{IgG}_{1}$, clone 18, dilution 1:1000, BD Biosciences, Heidelberg, Germany), CDK1 (Mouse IgG 1 , clone 2, dilution 1:2500, BD Biosciences, Heidelberg, Germany), CDK2 (Mouse $\operatorname{IgG}_{2 \mathrm{a}}$, clone 55, dilution 1:2500, BD Biosciences, Heidelberg, Germany), and pCDK2 (Rabbit, polyclonal antibody, dilution 1:1000, Cell Signaling, Frankfurt am Main, Germany).

To detect apoptosis- and necroptosis-related proteins, the following primary antibodies were used: Caspase 3 (Rabbit IgG, polyclonal antibody, dilution 1:1000), Caspase 8 (Rabbit IgG, clone D35G2, dilution 1:1000), PARP (Rabbit IgG, clone 46D11, dilution 1:1000), RIP1 (Rabbit IgG, clone D94C12, dilution 1:1000), pRIP1S166 (Rabbit IgG, clone D1L3S, dilution 1:1000), RIP3 (Rabbit IgG, clone E1Z1D, dilution 1:1000), pRIP3S227 (Rabbit IgG, clone D6W2T, dilution 1:1000), MLKL (Rabbit IgG, clone D2I6N, dilution 1:1000), and pMLKLS358 (Rabbit IgG, clone D6H3V, dilution 1:1000) (all Cell Signaling, Frankfurt am Main, Germany). HRP-conjugated rabbit-anti-mouse IgG or goat-anti-rabbit IgG served as secondary antibodies (IgG, both: dilution 1:1000, Dako, Glosturp, Denmark). The membranes were incubated with ECL detection reagent (AC2204, Azure Biosystems, Munich, Germany) to visualize proteins with a Sapphire Imager (Azure Biosystems, Munich, Germany). The exposure time was adapted to the signal intensity (device-specific maximum, $>65,000=$ oversaturated). Only images with a maximum band intensity of below 65,000 were used for evaluation. $\beta$-actin (clone AC-1, dilution 1:10,000, Sigma Aldrich, Taufkirchen, Germany) served as internal control for cell cycle regulating proteins. Cell death regulating proteins were normalized to total protein that was quantified by staining total protein from all membranes with Coomassie brilliant blue and measuring with a Sapphire Imager. AlphaView software (ProteinSimple, San Jose, CA, USA) was used for pixel density analysis of the protein bands. The ratio of protein intensity/ $\beta$-actin intensity or whole protein intensity was calculated and expressed in percentage, related to untreated controls, set to $100 \%$.

\subsection{Cell Death}

To investigate apoptotic and necrotic events the binding of Annexin $\mathrm{V} /$ propidium iodide (PI) in PC3, DU145 and LNCaP cells was quantified with the FITC-Annexin V Apoptosis Detection kit (BD Biosciences, Heidelberg, Germany). After washing tumor cells twice with PBS, $1 \times 10^{5}$ cells were suspended in $500 \mu \mathrm{L}$ of $1 \times$ binding buffer and incubated with $5 \mu \mathrm{L}$ Annexin V-FITC and (or) $5 \mu \mathrm{L}$ PI in the dark for $15 \mathrm{~min}$. Staining was measured by flow cytometer (Fortessa X20, BD Biosciences, Heidelberg, Germany). Ten-thousand events were collected from each sample. The percentage of apoptotic and necrotic cells in each quadrant was calculated using DIVA software (BD Biosciences, Heidelberg, Germany). Further analysis was done by FlowJo software (BD Biosciences, Heidelberg, Germany).

An L-Lactate dehydrogenase Cytotoxicity Assay Kit (Thermo Scientific, Waltham, MA, USA) was used to evaluate cell death/cytotoxicity of $22 \mathrm{Rv} 1$. Tumor cells ( $50 \mu \mathrm{L}$, $1 \times 10^{5}$ cells $/ \mathrm{mL}$ ) were seeded into 96-well plates and treated for $48 \mathrm{~h}$ with $50 \mu \mathrm{L} 0.5,0.75$, and $1.0 \mu \mathrm{M}$ SHI. After incubation, $50 \mu \mathrm{L}$ medium supernatant of treated cells was transferred to a new 96-well plate, mixed with a reaction solution for $30 \mathrm{~min}$, and then stopped with $50 \mu \mathrm{L}$ stop solution, according to the manufacturer's protocol. Absorbance was measured at $490 \mathrm{~nm}$ using a multimode microplate-reader (Tecan, Spark 10 M, Crailsheim, Germany). Values were presented as a percentage compared to untreated controls. 
Necroptotic effects were assessed using 3-(4,5-dimethylthiazol- 2-yl)-2,5-diphenyltetrazolium bromide (MTT) dye. To evaluate necroptosis, tumor cells were treated for $24 \mathrm{~h}$ and $48 \mathrm{~h}$ with $0.5,0.8$, and $1.0 \mu \mathrm{M}$ SHI or SHI combined with $80 \mu \mathrm{M}$ necrostatin-1 (SigmaAldrich, Darmstadt, Germany), a necroptosis inhibitor or with $20 \mu \mathrm{M}$ zVAD (Selleckchem, München, Deutschland), a multi-caspase inhibitor. For more details, see "Tumor Cell Growth" (Section 4.3).

\subsection{GSH-Assay}

The GSH level was evaluated with the GSH-Glo ${ }^{\mathrm{TM}}$ Glutathione Assay (Promega Corporation, Madison, WI, USA). Five-thousand cells/well were seeded onto a 96-well plate and incubated for $24 \mathrm{~h}$ with $0.5 \mu \mathrm{M}$ SHI. Experiments were performed according to the manufacturer's protocol. Luminescence was measured using a multimode microplatereader (Tecan, Spark 10 M, Tecan, Grödig, Austria).

\subsection{Evaluation of Mitochondrial Respiration and Anaerobic Glycolytic Activity}

Mitochondrial respiration (OCR = oxygen consumption rate) and anaerobic glycolytic activity (EACR = extracellular acidification rate) were assessed in real-time by the Seahorse XFp Extracellular Flux Analyzer using the Seahorse XF Cell Mito Stress Test Kit (both: Agilent Technologies, Waldbronn, Germany). The OCR is defined by multiple parameters, including basal respiration, ATP production-coupled respiration, maximal and reserve capacities, and non-mitochondrial respiration. Cells stained with CellTracker Green CMFDA (Thermo Fisher Scientific, Darmstadt, Germany) were plated at a density of $2 \times 10^{4}$ cells/well and media was replaced with XF Assay media the following day, $1 \mathrm{~h}$ prior to the assay and incubated without $\mathrm{CO}_{2}$. Five measurements of OCR and ECAR were done at baseline and 30 measurements after SHI injection. Data were normalized to the mean fluorescent intensity of cells in the area of measurement using Wave 2.6.1 (Agilent Technologies, Waldbronn, Germany) desktop software.

\subsection{Statistical Analysis}

All experiments were performed at least three times. The evaluation and generation of mean values, the associated standard deviation, and normalization in percent were done by Microsoft Excel. Statistical significance was calculated with GraphPad Prism 7.0 (GraphPad Software Inc., San Diego, CA, USA): two-sided $t$-test (Western blot, apoptosis, cell cycle), one-way ANOVA test (BrdU), and two-way ANOVA test (MTT). Correction for multiple comparison was done using the conservative Bonferroni method. Error bars indicate standard deviation (SD). Differences were considered statistically significant at a $p$-value $\leq 0.05$ with $^{*}=p \leq 0.05,{ }^{* *}=p \leq 0.01,{ }^{* * *}=p \leq 0.001$.

\section{Conclusions}

SHI induced a time- and dose-dependent inhibition of tumor cell growth and proliferation in a panel of parental and DX-resistant PCa cells. SHI's growth inhibitory effect was accompanied by necroptosis induction in all PCa cell lines, including the DX-resistant cell lines. Exposure to SHI triggered necroptosis by decreasing caspase 8 and increasing pRIP1 and pRIP3. Notably, in the more aggressive, androgen-insensitive PCa cells-PC3 and DU145, the strongest necroptotic effects were apparent. Furthermore, evidence is presented showing that SHI may reactivate the necroptotic action of DX in those cells. SHI also contributed to a cell type specific cell cycle arrest in the G2/M or S phase with corresponding modulations of the cell cycle regulating proteins. In regard to these findings, it is postulated that SHI could hold promise as a beneficial addition to the conventional treatment of advanced PCa. Further investigation is necessary to evaluate other possible in vitro antitumor effects of $\mathrm{SHI}$ and to verify these in vivo. 
Supplementary Materials: The following are available online at https:/ /www.mdpi.com/2072-669 4/13/4/882/s1, Figure S1: Detailed information about Figure 5-Protein expression profile of cell cycle regulating proteins in parental and DX-resistant PC3 cells, Figure S2: Detailed information about Figure 6-Protein expression profile of cell cycle regulating proteins in parental and DXresistant DU145 cells, Figure S3: Detailed information about Figure 8h-Protein expression profile of PARP in parental and DX-resistant DU145 cells, Figure S4: Detailed information about Figure 8iProtein expression profile of Caspase 3 in parental and DX-resistant DU145 cells, Figure S5: Detailed information about Figure 8j-Protein expression profile of Caspase 8 in parental and DX-resistant DU145 cells, Figure S6: Detailed information about Figure 10-Protein expression profile of RIP1, pRIP1, RIP3, pRIP3, MLKL and pMLKL in parental and DX-resistant PC3 and DU145 cells, Figure S7: Detailed information about Section 2.6-Shikonin showed no effects on metabolism.

Author Contributions: Conceptualization, E.J.; methodology, S.D.M., K.M.J., K.H., P.S., K.S.S. and A.T.; software, S.D.M., K.M.J. and O.V.; validation, S.D.M., O.V. and T.E.; formal analysis, S.D.M., K.M.J. and E.J.; investigation, E.J.; resources, E.J., M.M., J.C. Jr. and T.E.; data curation, O.V.; writingoriginal draft preparation, S.D.M.; writing-review and editing, E.J., I.T., A.H. and T.E.; visualization, S.D.M.; supervision, E.J.; project administration, E.J.; funding acquisition, E.J., M.M. and J.C. Jr. All authors have read and agreed to the published version of the manuscript.

Funding: This research was funded by the Friedrich-Spicker-Stiftung (E.J.), grant number 01-2017; Hilfe für krebskranke Kinder Frankfurt e.V. (J.C. Jr.), Frankfurter Stiftung für krebskranke Kinder (J.C. Jr.), Kent Cancer Trust (M.M.).

Institutional Review Board Statement: Not applicable.

Informed Consent Statement: Not applicable.

Data Availability Statement: The data presented in this study are available in this article and Supplementary Materials.

Acknowledgments: The main portion of the results presented here are part of the medical doctor thesis of K.M.J. at the Department of Urology and Pediatric Urology (University Medical Center Mainz, Langenbeckstraße 1, 55131 Mainz, Germany). Some elements stem from the bachelor thesis of K.H. and the master thesis of P.S.

Conflicts of Interest: The authors declare no conflict of interest.

\section{References}

1. Cornford, P.; Bellmunt, J.; Bolla, M.; Briers, E.; De Santis, M.; Gross, T.; Henry, A.M.; Joniau, S.; Lam, T.B.; Mason, M.D.; et al. EAU-ESTRO-SIOG Guidelines on Prostate Cancer. Part II: Treatment of Relapsing, Metastatic, and Castration-Resistant Prostate Cancer. Eur. Urol. 2017, 71, 630-642. [CrossRef] [PubMed]

2. Tannock, I.F.; De Wit, R.; Berry, W.R.; Horti, J.; Pluzanska, A.; Chi, K.N.; Oudard, S.; Theodore, C.; James, N.D.; Turesson, I.; et al. Docetaxel plus Prednisone or Mitoxantrone plus Prednisone for Advanced Prostate Cancer. N. Engl. J. Med. 2004, 351, 1502-1512. [CrossRef] [PubMed]

3. Fizazi, K.; Faivre, L.; Lesaunier, F.; Delva, R.; Gravis, G.; Rolland, F.; Priou, F.; Ferrero, J.-M.; Houede, N.; Mourey, L.; et al. Androgen deprivation therapy plus docetaxel and estramustine versus androgen deprivation therapy alone for high-risk localised prostate cancer (GETUG 12): A phase 3 randomised controlled trial. Lancet Oncol. 2015, 16, 787-794. [CrossRef]

4. Rosenthal, S.A.; Hu, C.; Sartor, O.; Gomella, L.G.; Amin, M.B.; Purdy, J.; Michalski, J.M.; Garzotto, M.G.; Pervez, N.; Balogh, A.G.; et al. Effect of Chemotherapy With Docetaxel With Androgen Suppression and Radiotherapy for Localized High-Risk Prostate Cancer: The Randomized Phase III NRG Oncology RTOG 0521 Trial. J. Clin. Oncol. 2019, 37, 1159-1168. [CrossRef]

5. Armstrong, A.; Garrett-Mayer, E.; De Wit, R.; Tannock, I.; Eisenberger, M. Prediction of Survival following First-Line Chemotherapy in Men with Castration-Resistant Metastatic Prostate Cancer. Clin. Cancer Res. 2009, 16, 203-211. [CrossRef]

6. Thelen, P.; Gschwend, J.; Wolff, J.-M.; Miller, K. Resistenzmechanismen unter antihormoneller Therapie des fortgeschrittenen Prostatakarzinoms. Aktuel. Urol. 2016, 47, 79-85. [CrossRef] [PubMed]

7. Poonthananiwatkul, B.; Howard, R.L.; Williamson, E.M.; Lim, R.H. Cancer patients taking herbal medicines: A review of clinical purposes, associated factors, and perceptions of benefit or harm. J. Ethnopharmacol. 2015, 175, 58-66. [CrossRef]

8. Saghatchian, M.; Bihan, C.; Chenailler, C.; Mazouni, C.; Dauchy, S.; Delaloge, S. Exploring frontiers: Use of complementary and alternative medicine among patients with early-stage breast cancer. Breast 2014, 23, 279-285. [CrossRef]

9. Ebel, M.-D.; Rudolph, I.; Keinki, C.; Hoppe, A.; Muecke, R.; Micke, O.; Muenstedt, K.; Huebner, J. Perception of cancer patients of their disease, self-efficacy and locus of control and usage of complementary and alternative medicine. J. Cancer Res. Clin. Oncol. 2015, 141, 1449-1455. [CrossRef] 
10. Horneber, M.; Bueschel, G.; Dennert, G.; Less, D.; Ritter, E.; Zwahlen, M. How Many Cancer Patients Use Complementary and Alternative Medicine. Integr. Cancer Ther. 2011, 11, 187-203. [CrossRef]

11. Huebner, J.; Micke, O.; Muecke, R.; Buentzel, J.; Prott, F.J.; Kleeberg, U.; Senf, B.; Muenstedt, K. User rate of comple-mentary and alternative medicine (CAM) of patients visiting a counseling facility for CAM of a German comprehensive cancer center. Anticancer Res. 2014, 34, 943-948. [PubMed]

12. Christensen, C.M.; Morris, R.S.; Kapsandoy, S.C.; Archer, M.; Kuang, J.; Shane-McWhorter, L.; Bray, B.E.; Zeng-Treitler, Q. Patient needs and preferences for herb-drug-disease interaction alerts: A structured interview study. BMC Complement. Altern. Med. 2017, 17, 272. [CrossRef] [PubMed]

13. Mani, J.; Juengel, E.; Arslan, I.; Bartsch, G.; Filmann, N.; Ackermann, H.; Nelson, K.; Haferkamp, A.; Engl, T.; Blaheta, R.A. Use of complementary and alternative medicine before and after organ removal due to urologic cancer. Patient Prefer. Adherence 2015, 9 , 1407-1412. [CrossRef]

14. Kessel, K.A.; Lettner, S.; Kessel, C.; Bier, H.; Biedermann, T.; Friess, H.; Herrschbach, P.; Gschwend, J.E.; Meyer, B.; Peschel, C.; et al. Use of Complementary and Alternative Medicine (CAM) as Part of the Oncological Treatment: Survey about Patients' Attitude towards CAM in a University-Based Oncology Center in Germany. PLoS ONE 2016, 11, e0165801. [CrossRef] [PubMed]

15. Juengel, E.; Thomas, A.; Rutz, J.; Makarevic, J.; Tsaur, I.; Nelson, K.; Haferkamp, A.; Blaheta, R.A. Amygdalin inhibits the growth of renal cell carcinoma cells in vitro. Int. J. Mol. Med. 2015, 37, 526-532. [CrossRef]

16. Rutz, J.; Maxeiner, S.; Juengel, E.; Bernd, A.; Kippenberger, S.; Zöller, N.; Chun, F.K.-H.; Blaheta, R.A. Growth and Proliferation of Renal Cell Carcinoma Cells Is Blocked by Low Curcumin Concentrations Combined with Visible Light Irradiation. Int. J. Mol. Sci. 2019, 20, 1464. [CrossRef]

17. Lee, H.M.; Moon, A. Amygdalin Regulates Apoptosis and Adhesion in Hs578T Triple-Negative Breast Cancer Cells. Biomol. Ther. 2016, 24, 62-66. [CrossRef]

18. Wang, F.; Wang, W.; Li, J.; Zhang, J.; Wang, X.; Wang, M. Sulforaphane reverses gefitinib tolerance in human lung cancer cells via modulation of sonic hedgehog signaling. Oncol. Lett. 2017, 15, 109-114. [CrossRef] [PubMed]

19. Yang, C.; Ma, X.; Wang, Z.; Zeng, X.; Hu, Z.; Ye, Z.; Shen, G. Curcumin induces apoptosis and protective autophagy in castration-resistant prostate cancer cells through iron chelation. Drug Des. Dev. Ther. 2017, 11, 431-439. [CrossRef]

20. Singh, S.K. Combinatorial effect of curcumin with docetaxel modulates apoptotic and cell survival molecules in prostate cancer. Front. Biosci. 2017, 9, 235-245. [CrossRef]

21. Markowitsch, S.D.; Schupp, P.; Lauckner, J.; Vakhrusheva, O.; Slade, K.S.; Mager, R.; Efferth, T.; Haferkamp, A.; Juengel, E. Artesunate Inhibits Growth of Sunitinib-Resistant Renal Cell Carcinoma Cells through Cell Cycle Arrest and Induction of Ferroptosis. Cancers 2020, 12, 3150. [CrossRef]

22. Papageorgiou, V.P.; Assimopoulou, A.N.; Couladouros, E.A.; Hepworth, D.; Nicolaou, K.C. The Chemistry and Biology of Alkannin, Shikonin, and Related Naphthazarin Natural Products. Angew. Chem. Int. Ed. 1999, 38, 270-301. [CrossRef]

23. Lu, L.; Qin, A.; Huang, H.; Zhou, P.; Zhang, C.; Liu, N.; Li, S.; Wen, G.; Zhang, C.; Dong, W.; et al. Shikonin extracted from medicinal Chinese herbs exerts anti-inflammatory effect via proteasome inhibition. Eur. J. Pharmacol. 2011, 658, $242-247$. [CrossRef] [PubMed]

24. Thonsri, U.; Seubwai, W.; Waraasawapati, S.; Wongkham, S.; Boonmars, T.; Cha'On, U.; Wongkham, C. Antitumor Effect of Shikonin, a PKM2 Inhibitor, in Cholangiocarcinoma Cell Lines. Anticancer. Res. 2020, 40, 5115-5124. [CrossRef] [PubMed]

25. Wang, F.; Pozo, F.M.; Tian, D.; Geng, X.; Yao, X.; Zhang, Y.; Tang, J. Shikonin Inhibits Cancer Through P21 Upregulation and Apoptosis Induction. Front. Pharmacol. 2020, 11, 861. [CrossRef] [PubMed]

26. Kim, S.-J.; Kim, J.M.; Shim, S.H.; Chang, H.I. Shikonin induces cell cycle arrest in human gastric cancer (AGS) by early growth response 1 (Egr1)-mediated p21 gene expression. J. Ethnopharmacol. 2014, 151, 1064-1071. [CrossRef]

27. Liang, W.; Cai, A.; Chen, G.; Xi, H.; Wu, X.; Cui, J.; Zhang, K.; Zhao, X.; Yu, J.; Wei, B.; et al. Shikonin induces mitochondriamediated apoptosis and enhances chemotherapeutic sensitivity of gastric cancer through reactive oxygen species. Sci. Rep. 2016, 6, 38267. [CrossRef]

28. Chen, C.; Xiao, W.; Huang, L.; Yu, G.; Ni, J.; Yang, L.; Wan, R.; Hu, G. Shikonin induces apoptosis and necroptosis in pancreatic cancer via regulating the expression of RIP1/RIP3 and synergizes the activity of gemcitabine. Am. J. Transl. Res. 2017, 9, 5507-5517.

29. Kim, H.-J.; Hwang, K.-E.; Park, D.-S.; Oh, S.-H.; Jun, H.Y.; Yoon, K.-H.; Jeong, E.-T.; Kim, H.-R.; Kim, Y.-S. Shikonin-induced necroptosis is enhanced by the inhibition of autophagy in non-small cell lung cancer cells. J. Transl. Med. 2017, 15, 1-12. [CrossRef]

30. Ding, Y.; He, C.; Lu, S.; Wang, X.; Wang, C.; Wang, L.; Zhang, J.; Piao, M.; Chi, G.; Luo, Y.; et al. MLKL contributes to shikonin-induced glioma cell necroptosis via promotion of chromatinolysis. Cancer Lett. 2019, 467, 58-71. [CrossRef]

31. Shahsavari, Z.; Karami-Tehrani, F.; Salami, S.; Ghasemzadeh, M. RIP1K and RIP3K provoked by shikonin induce cell cycle arrest in the triple negative breast cancer cell line, MDA-MB-468: Necroptosis as a desperate programmed suicide pathway. Tumor Biol. 2015, 37, 4479-4491. [CrossRef] [PubMed]

32. Dhuriya, Y.K.; Sharma, D. Necroptosis: A regulated inflammatory mode of cell death. J. Neuroinflamm. 2018, 15, 1-9. [CrossRef] [PubMed]

33. Gong, Y.; Fan, Z.; Luo, G.; Yang, C.; Huang, Q.; Fan, K.; Cheng, H.; Jin, K.; Ni, Q.; Yu, X.; et al. The role of necroptosis in cancer biology and therapy. Mol. Cancer 2019, 18, 1-17. [CrossRef] 
34. Wang, Y.; Hao, F.; Nan, Y.; Qu, L.; Na, W.; Jia, C.; Chen, X. PKM2 Inhibitor Shikonin Overcomes the Cisplatin Resistance in Bladder Cancer by Inducing Necroptosis. Int. J. Biol. Sci. 2018, 14, 1883-1891. [CrossRef] [PubMed]

35. Huang, X.; Jin, J.; Qian, W.; Ye, X. Shikonin Overcomes Drug Resistance and Induces Necroptosis By Regulating the Mir-92a-15p/Mlkl Axis in Chronic Myeloid Leukemia Cells. Blood 2019, 134, 1633. [CrossRef]

36. Tang, J.-C.; Ren, Y.-G.; Zhao, J.; Long, F.; Chen, J.-Y.; Jiang, Z. Shikonin enhances sensitization of gefitinib against wild-type EGFR non-small cell lung cancer via inhibition PKM2/stat3/cyclinD1 signal pathway. Life Sci. 2018, 204, 71-77. [CrossRef]

37. Zhao, X.; Zhu, Y.; Hu, J.; Jiang, L.; Li, L.; Jia, S.; Zen, K. Shikonin Inhibits Tumor Growth in Mice by Suppressing Pyruvate Kinase M2-mediated Aerobic Glycolysis. Sci. Rep. 2018, 8, 1-8. [CrossRef]

38. Wiench, B.; Eichhorn, T.; Paulsen, M.; Efferth, T. Shikonin Directly Targets Mitochondria and Causes Mitochondrial Dysfunction in Cancer Cells. Evid.-Based Complement. Altern. Med. 2012, 2012,1-15. [CrossRef] [PubMed]

39. Otto, T.; Sicinski, T.O.P. Cell cycle proteins as promising targets in cancer therapy. Nat. Rev. Cancer 2017, 17, 93-115. [CrossRef]

40. Ingham, M.; Schwartz, G.K. Cell-Cycle Therapeutics Come of Age. J. Clin. Oncol. 2017, 35, 2949-2959. [CrossRef]

41. Ogura, T.; Tanaka, Y.; Tamaki, H.; Harada, M. Docetaxel induces Bcl-2- and pro-apoptotic caspase-independent death of human prostate cancer DU145 cells. Int. J. Oncol. 2016, 48, 2330-2338. [CrossRef] [PubMed]

42. Jeung, Y.-J.; Kim, H.-G.; Ahn, J.; Lee, H.-J.; Lee, S.-B.; Won, M.; Jung, C.-R.; Im, J.-Y.; Kim, B.-K.; Park, S.-K.; et al. Shikonin induces apoptosis of lung cancer cells via activation of FOXO3a/EGR1/SIRT1 signaling antagonized by p300. Biochim. Biophys. Acta BBA Bioenergy 2016, 1863, 2584-2593. [CrossRef] [PubMed]

43. Zhai, T.; Hei, Z.; Ma, Q.; Liang, H.; Xu, Y.; Zhang, Y.; Jin, L.; Han, C.; Wang, J. Shikonin induces apoptosis and G0/G1ï $\frac{1}{2}$ phase arrest of gallbladder cancer cells via the JNK signaling pathway. Oncol. Rep. 2017, 38, 3473-3480. [CrossRef]

44. Du, W.; Hao, X.; Yuan, Z.; Wang, Y.; Zhang, X.; Liu, J. Shikonin potentiates paclitaxel antitumor efficacy in esophageal cancer cells via the apoptotic pathway. Oncol. Lett. 2019, 18, 3195-3201. [CrossRef] [PubMed]

45. Wei, Y.; Li, M.; Cui, S.; Wang, D.; Zhang, C.-Y.; Zen, K.; Li, L. Shikonin Inhibits the Proliferation of Human Breast Cancer Cells by Reducing Tumor-Derived Exosomes. Molecules 2016, 21, 777. [CrossRef]

46. Zhang, Z.; Zhang, Z.; Li, Q.; Jiao, H.; Chong, D.; Sun, X.; Zhang, P.; Huo, Q.; Liu, H. Shikonin induces necroptosis by reactive oxygen species activation in nasopharyngeal carcinoma cell line CNE-2Z. J. Bioenerg. Biomembr. 2017, 49, 265-272. [CrossRef] [PubMed]

47. Chen, Y.; Zheng, L.; Liu, J.; Zhou, Z.; Cao, X.; Lv, X.; Chen, F. Shikonin inhibits prostate cancer cells metastasis by reducing matrix metalloproteinase-2/-9 expression via AKT/mTOR and ROS/ERK1/2 pathways. Int. Immunopharmacol. 2014, 21, 447-455. [CrossRef]

48. Jang, S.Y.; Jang, E.H.; Jeong, S.Y.; Kim, J.-H. Shikonin inhibits the growth of human prostate cancer cells via modulation of the androgen receptor. Int. J. Oncol. 2014, 44, 1455-1460. [CrossRef]

49. Liu, Y.; Kang, X.; Niu, G.; He, S.; Zhang, T.; Bai, Y.; Li, Y.; Hao, H.; Chen, C.; Shou, Z.; et al. Shikonin induces apoptosis and prosurvival autophagy in human melanoma A375 cells via ROS-mediated ER stress and p38 pathways. Artif. Cells Nanomed. Biotechnol. 2019, 47, 626-635. [CrossRef]

50. Trochon, V.; Blot, E.; Cymbalista, F.; Engelmann, C.; Tang, R.P.; Thomaïdis, A.; Vasse, M.; Soria, J.; Lu, H.; Soria, C. Apigenin inhibits endothelial-cell proliferation in G2/M phase whereas it stimulates smooth-muscle cells by inhibiting P21 and P27 expression. Int. J. Cancer 2000, 85, 691-696. [CrossRef]

51. Yadav, V.; Sultana, S.; Yadav, J.; Saini, N. Gatifloxacin Induces S and G2-Phase Cell Cycle Arrest in Pancreatic Cancer Cells via p21/p27/p53. PLoS ONE 2012, 7, e47796. [CrossRef] [PubMed]

52. Gavet, O.; Pines, J. Progressive activation of CyclinB1-Cdk1 coordinates entry to mitosis. Dev. Cell. 2010, 18, 533-543. [CrossRef]

53. Tang, J.-C.; Zhao, J.; Long, F.; Chen, J.-Y.; Mu, B.; Jiang, Z.; Ren, Y.; Yang, J. Efficacy of Shikonin against Esophageal Cancer Cells and its possible mechanisms in vitro and in vivo. J. Cancer 2018, 9, 32-40. [CrossRef] [PubMed]

54. Zhao, Q.; Assimopoulou, A.N.; Klauck, S.M.; Damianakos, H.; Chinou, I.; Kretschmer, N.; Ríos, J.-L.; Papageorgiou, V.P.; Bauer, R.; Efferth, T. Inhibition of c-MYC with involvement of ERK/JNK/MAPK and AKT pathways as a novel mechanism for shikonin and its derivatives in killing leukemia cells. Oncotarget 2015, 6, 38934-38951. [CrossRef] [PubMed]

55. Fu, Z.; Deng, B.; Liao, Y.; Shan, L.; Yin, F.; Wang, Z.; Zeng, H.; Zuo, D.; Hua, Y.; Cai, Z. The anti-tumor effect of shikonin on osteosarcoma by inducing RIP1 and RIP3 dependent necroptosis. BMC Cancer 2013, 13, 580. [CrossRef]

56. Lee, M.-J.; Kao, S.-H.; Hunag, J.-E.; Sheu, G.-T.; Yeh, C.-W.; Hseu, Y.-C.; Wang, C.-J.; Hsu, L.-S. Shikonin time-dependently induced necrosis or apoptosis in gastric cancer cells via generation of reactive oxygen species. Chem. Interact. 2014, 211, 44-53. [CrossRef]

57. Diao, Y.; Ma, X.; Min, W.; Lin, S.; Kang, H.; Dai, Z.; Wang, X.; Zhao, Y. Dasatinib promotes paclitaxel-induced necroptosis in lung adenocarcinoma with phosphorylated caspase-8 by c-Src. Cancer Lett. 2016, 379, 12-23. [CrossRef]

58. Mann, J.; Yang, N.; Montpetit, R.; Kirschenman, R.; Lemieux, H.; Goping, I.S. BAD sensitizes breast cancer cells to docetaxel with increased mitotic arrest and necroptosis. Sci. Rep. 2020, 10, 1-11. [CrossRef]

59. Wu, X.; Wu, M.-Y.; Jiang, M.; Zhi, Q.; Bian, X.; Xu, M.-D.; Gong, F.-R.; Hou, J.; Tao, M.; Shou, L.-M.; et al. TNF- $\alpha$ sensitizes chemotherapy and radiotherapy against breast cancer cells. Cancer Cell Int. 2017, 17, 1-12. [CrossRef]

60. Zhao, Q.; Kretschmer, N.; Bauer, R.; Efferth, T. Shikonin and its derivatives inhibit the epidermal growth factor receptor signaling and synergistically kill glioblastoma cells in combination with erlotinib. Int. J. Cancer 2015, 137, 1446-1456. [CrossRef] [PubMed]

61. Wu, H.; Xie, J.; Pan, Q.; Wang, B.; Hu, D.; Hu, X. Anticancer Agent Shikonin Is an Incompetent Inducer of Cancer Drug Resistance. PLoS ONE 2013, 8, e52706. [CrossRef] 
62. Lu, B.; Gong, X.; Wang, Z.-Q.; Ding, Y.; Wang, C.; Luo, T.-F.; Piao, M.-H.; Meng, F.-K.; Chi, G.-F.; Luo, Y.-N.; et al. Shikonin induces glioma cell necroptosis in vitro by ROS overproduction and promoting RIP1/RIP3 necrosome formation. Acta Pharmacol. Sin. 2017, 38, 1543-1553. [CrossRef]

63. Rodriguez, D.; Weinlich, R.; Brown, S.L.; Guy, C.T.; Fitzgerald, P.J.; Dillon, C.P.; Oberst, A.; Quarato, G.; Low, J.; Cripps, J.G.; et al. Characterization of RIPK3-mediated phosphorylation of the activation loop of MLKL during necroptosis. Cell Death Differ. 2016, 23, 76-88. [CrossRef] [PubMed]

64. Zhou, Z.; Lu, B.; Wang, C.; Wang, Z.; Luo, T.; Piao, M.; Meng, F.; Chi, G.; Luo, Y.; Ge, P. RIP1 and RIP3 contribute to shikonininduced DNA double-strand breaks in glioma cells via increase of intracellular reactive oxygen species. Cancer Lett. 2017, 390, 77-90. [CrossRef] [PubMed]

65. Horoszewicz, J.S.; Leong, S.S.; Kawinski, E.; Karr, J.P.; Rosenthal, H.; Chu, T.M.; A Mirand, E.; Murphy, G.P. LNCaP model of human prostatic carcinoma. Cancer Res. 1983, 43, 1809-1818. [PubMed]

66. Alimirah, F.; Chen, J.; Basrawala, Z.; Xin, H.; Choubey, D. DU-145 and PC-3 human prostate cancer cell lines express androgen receptor: Implications for the androgen receptor functions and regulation. FEBS Lett. 2006, 580, 2294-2300. [CrossRef]

67. Wen, S.; Niu, Y.; Lee, S.O.; Chang, C. Androgen receptor (AR) positive vs negative roles in prostate cancer cell deaths including apoptosis, anoikis, entosis, necrosis and autophagic cell death. Cancer Treat. Rev. 2014, 40, 31-40. [CrossRef]

68. Metzig, M.O.; Fuchs, D.; E Tagscherer, K.; Grone, H.; Schirmacher, P.; Roth, W. Inhibition of caspases primes colon cancer cells for 5-fluorouracil-induced TNF- $\alpha$-dependent necroptosis driven by RIP1 kinase and NF-кB. Oncogene 2016, 35, 3399-3409. [CrossRef]

69. Xu, Y.; Ma, H.-B.; Fang, Y.-L.; Zhang, Z.-R.; Shao, J.; Hong, M.; Huang, C.-J.; Liu, J.; Chen, R.-Q. Cisplatin-induced necroptosis in $\mathrm{TNF} \alpha$ dependent and independent pathways. Cell. Signal. 2017, 31, 112-123. [CrossRef]

70. Chen, J.; Xie, J.; Jiang, Z.; Wang, B.; Wang, Y.; Hu, X. Shikonin and its analogs inhibit cancer cell glycolysis by targeting tumor pyruvate kinase-M2. Oncogene 2011, 30, 4297-4306. [CrossRef]

71. Shimada, N.; Takasawa, R.; Tanuma, S.-I. Interdependence of GLO I and PKM2 in the Metabolic shift to escape apoptosis in GLO I-dependent cancer cells. Arch. Biochem. Biophys. 2018, 638, 1-7. [CrossRef]

72. Shahsavari, Z.; Karami-Tehrani, F.; Salami, S. Shikonin Induced Necroptosis via Reactive Oxygen Species in the T-47D Breast Cancer Cell Line. Asian Pac. J. Cancer Prev. 2015, 16, 7261-7266. [CrossRef] [PubMed]

73. Michaelis, M.; Wass, M.N.; Cinatl, J. Drug-adapted cancer cell lines as preclinical models of acquired resistance. Cancer Drug Resist. 2019, 2, 447-456. [CrossRef]

74. Michaelis, M.; Rothweiler, F.; Barth, S.; Cinatl, J.; Van Rikxoort, M.; Löschmann, N.; Voges, Y.; Breitling, R.; Von Deimling, A.; Rödel, F; et al. Adaptation of cancer cells from different entities to the MDM2 inhibitor nutlin-3 results in the emergence of p53-mutated multi-drug-resistant cancer cells. Cell Death Dis. 2011, 2, e243. [CrossRef] [PubMed] 